\title{
Antisense Oligodeoxynucleotide Perfusion Blocks Gene Expression of Synaptic Plasticity-related Proteins without Inducing Compensation in Hippocampal Slices Panayiotis Tsokas ${ }^{1,2, *}$, Bruno Rivard ${ }^{1, \$}$, Changchi Hsieh ${ }^{1}$, James E. Cottrell ${ }^{2}$, André Antonio Fenton ${ }^{1,3}$ and Todd Charlton Sacktor ${ }^{1,2,4}$
}

\begin{abstract}
1Department of Physiology and Pharmacology, The Robert F. Furchgott Center for Neural and Behavioral Science, State University of New York Downstate Medical Center, Brooklyn, United States; 2Department of Anesthesiology, State University of New York Downstate Medical Center, Brooklyn, United States; ${ }^{3}$ Center for Neural Science, New York University, New York, United States; ${ }^{4}$ Department of Neurology, State University of New York Downstate Medical Center, Brooklyn, United States; ${ }^{\$}$ Current address: Department of Psychiatry, Douglas Mental Health University Institute, McGill University, Montreal, Canada
\end{abstract}

*For correspondence: Panayiotis.Tsokas@downstate.edu

[Abstract] The elucidation of the molecular mechanisms of long-term synaptic plasticity has been hindered by both the compensation that can occur after chronic loss of the core plasticity molecules and by ex vivo conditions that may not reproduce in vivo plasticity. Here we describe a novel method to rapidly suppress gene expression by antisense oligodeoxynucleotides (ODNs) applied to rodent brain slices in an "Oslo-type" interface chamber. The method has three advantageous features: 1) rapid blockade of new synthesis of the targeted proteins that avoids genetic compensation, 2) efficient oxygenation of the brain slice, which is critical for reproducing in vivo conditions of long-term synaptic plasticity, and 3) a recirculation system that uses only small volumes of bath solution $(<5 \mathrm{ml})$, reducing the amount of reagents required for long-term experiments lasting many hours. The method employs a custom-made recirculation system involving piezoelectric micropumps and was first used for the acute translational blockade of protein kinase $M \zeta(P K M \zeta)$ synthesis during long-term potentiation (LTP) by Tsokas et al., 2016. In that study, applying antisense-ODN rapidly prevents the synthesis of PKM 3 and blocks late-LTP without inducing the compensation by other protein kinase $C$ (PKC) isoforms that occurs in $\mathrm{PKC \zeta /PKM \zeta} \mathrm{knockout} \mathrm{mice.} \mathrm{In} \mathrm{addition,} \mathrm{we} \mathrm{show} \mathrm{that} \mathrm{in} \mathrm{a} \mathrm{low-oxygenation} \mathrm{submersion-type}$ chamber, applications of the atypical PKC inhibitor, zeta inhibitory peptide (ZIP), can result in unstable baseline synaptic transmission, but in the high-oxygenation, "Oslo-type" interface electrophysiology chamber, the drug reverses late-LTP without affecting baseline synaptic transmission. This comparison reveals that the interface chamber, but not the submersion chamber, reproduces the effects of ZIP in vivo. Therefore, the protocol combines the ability to acutely block new synthesis of specific proteins for the study of long-term synaptic plasticity, while maintaining properties of synaptic transmission that reproduce in vivo conditions relevant for long-term memory.

Keywords: Long-Term Potentiation, LTP, Piezoelectric micropump, PKM , PKM- $\zeta$, ZIP

[Background] Ex vivo acute brain slices have been a useful experimental model for studies of neural 
function at the molecular, cellular, and circuit levels. Advances in knockout techniques have also greatly facilitated the generation of genetically modified mice. Hippocampal slices from these mutant mice have become one of the most widely used experimental paradigms for studying both normal synaptic plasticity and its dysfunction in animal models of human psychiatric and neurological disorders.

Several studies, however, have revealed that genetic compensation in response to gene knockout is a widespread phenomenon (for review, see El-Brolosy and Stainier, 2017). Upregulation of related genes following gene knockout can either attenuate or completely compensate for the function of the deleted gene, leading to experimental findings that can be misinterpreted.

Such compensation can be avoided by acutely blocking the de novo synthesis of the target gene product with a brief application of antisense oligodeoxynucleotides (ODNs). ODNs are short single-stranded synthetic DNA molecules, often modified with phosphorothioate linkages to enhance stability. ODNs can bind to complementary regions of a specific mRNA, usually located near the translation start site (AUG, in Figure 1A, top), and physically block the ability of ribosomes to move along the mRNA, preventing synthesis of the protein. Because the effects of ODNs are rapid, the possibility of altered regulation of other genes that can occur with more prolonged gene deletion is reduced. Potential off-target effects may occur, but can be minimized with the appropriate design of the ODN and by pharmacogenetic experiments employing ODNs together with knockouts that lack the target mRNA (Tsokas et al., 2016).

Most previous studies employing ODNs to suppress gene expression in brain slices, however, first infuse the ODN into the brain by intracranial or intraventricular injection, and then soon after the injection prepare the tissue slice (Matthies et al., 1995; Guzowski et al., 2000; Garcia-Osta et al., 2006). Although effective in introducing the ODN into the brain, the injection itself often damages the neural tissue, resulting in suboptimal recordings from brain slices prepared adjacent to the injection site. In addition, the injection delivers the compound as a bolus at a high concentration that then must diffuse through the brain tissue in the intact animal prior to the slice preparation. As a result, the experimenter does not have precise control over the concentration of the compound present in the slice at the time of recording. If a high drug concentration in the bolus injection is required, this in turn can lead to questions about pharmacological specificity.

The method described in this protocol renders the perfusion of brain slices with antisense-ODN as easy as the application of any other soluble reagent or drug. Therefore, the technique may be preferable to the standard method of intracranial or intraventricular injections followed by preparing brain slices. In addition, electrophysiological recordings are in an "Oslo-type" interface brain slice recording chamber. Interface chambers are preferable to submersion chambers for long-term recordings of brain slices because they provide superior oxygenation (for detailed discussion, see Note 1). This protocol was first used in Tsokas et al. (2016) to block specifically the new synthesis of protein kinase $M \zeta(P K M \zeta)$ in response to strong afferent tetanic stimulation (high-frequency stimulation, HFS) without inducing genetic compensation by the other atypical protein kinase $C(P K C)$ isoform, $P K C_{1} / \lambda$, as occurs in PKM -null mice. Indeed, in these mutant mice, long-term potentiation (LTP) and memory formation appear largely intact because the normal physiological function of PKM 
compensated by $\mathrm{PKC} / / \lambda$ (Tsokas et al., 2016).

Genetic compensation for LTP and spatial long-term memory in PKM -null mice was revealed in Tsokas et al. (2016) by a pharmacogenetic analysis of wild-type and PKM -null mice using PKM -antisense ODN. In these experiments, the normal physiological function of PKM $\zeta$ was selectively blocked by taking advantage of the specific nucleotide sequence of the PKM $-m R N A$ translation start site to design a PKM -antisense ODN (Figure 1A) that suppresses the activity-dependent de novo

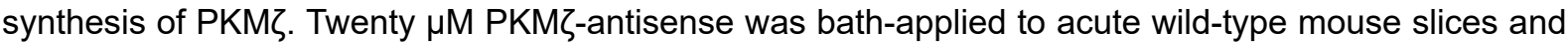
recirculated for $1 \mathrm{~h}$ before tetanization and during the critical period of new protein synthesis after tetanization when $\mathrm{PKM} \zeta$ is formed (Osten et al., 1996), i.e., during the temporal window when general protein synthesis inhibitors such as anisomycin are effective in blocking late-LTP induction (Frey and

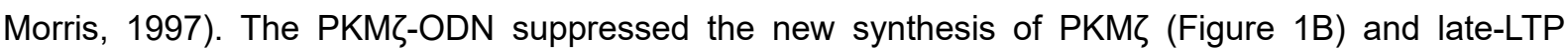
(Figure $1 \mathrm{C}$ ) without affecting the upregulation of $\mathrm{PKC} / \mathrm{A}$ or the eukaryotic elongation factor $1 \mathrm{~A}(\mathrm{eEF} 1 \mathrm{~A})$, proteins that are also rapidly synthesized in LTP (Tsokas et al., 2016; Figure 1B). Because the turnover of PKM is relatively slow (Osten et al., 1996), basal amounts of PKM unaffected (Tsokas et al., 2016). The application of PKM mice, in which the target of the PKM -antisense is absent (Figure 1C). These results demonstrate that in the mutant mice another molecule compensates for the loss of PKM . Conversely, a selective $\mathrm{PKC} / / \lambda$ inhibitor reversed established LTP only in the PKM -null mice and not in wild-type mice (Tsokas et al., 2016, Figure 3). This double dissociation between the mechanisms of LTP in PKM -null and wild-type mice revealed that when PKM $\zeta$ is absent there is functional compensation by $P K C_{1} / \lambda$.
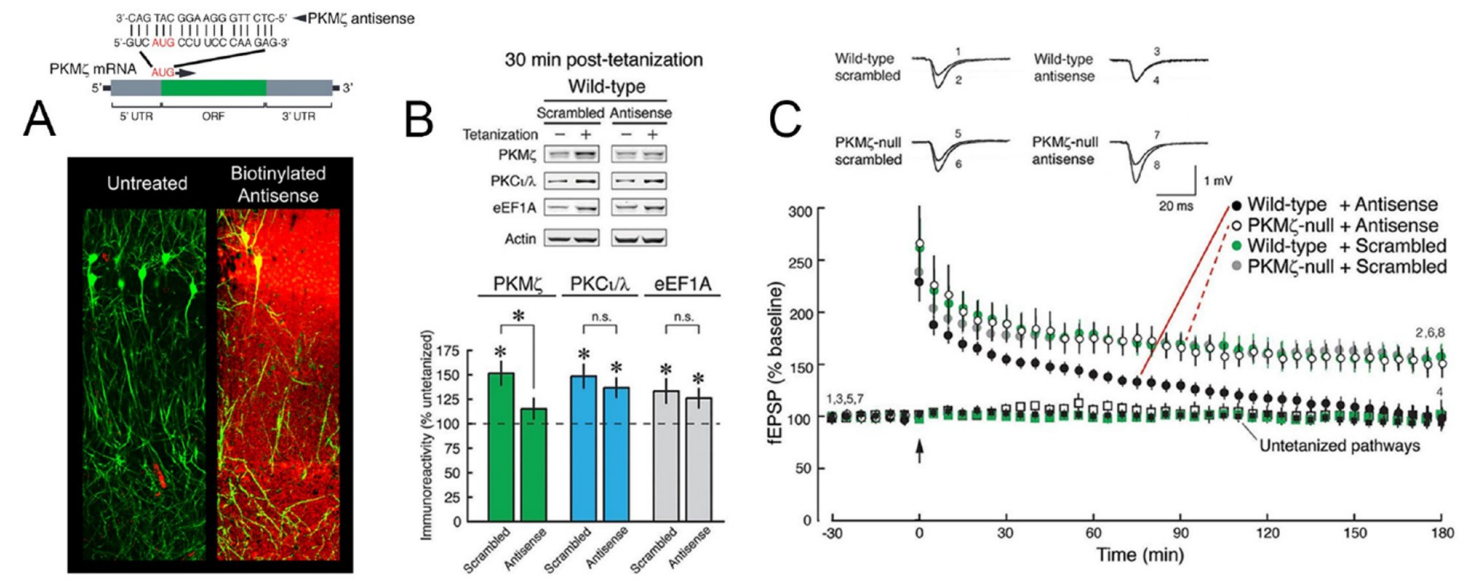

Figure 1. Acute perfusion of mouse hippocampal slices with PKM -antisense ODN (20 $\mu \mathrm{M})$ via the mp6 micropump system reveals that PKM


PKM -antisense. Bottom: Bath pre-application and recirculation of $20 \mu \mathrm{M}$ biotinylated PKM $\zeta$-antisense in ACSF for $1 \mathrm{~h}$ in Tg(Thy1-EGFP)MJrs/J mouse hippocampal slices allows highly efficient penetration of the ODN in pyramidal EGFP-filled neurons (green), as verified with cy3-conjugated streptavidin staining of biotinylated ODN (red) post-fixation. B. Bath-applied $\mathrm{PKM} \zeta$-antisense blocks new synthesis of $\mathrm{PKM} \zeta$, but not $\mathrm{PKC}_{\mathrm{l}} / \lambda$ or the eukaryotic elongation factor 
1A (eEF1A) that are also synthesized in LTP. C. Bath-applied PKM -antisense blocks late-LTP in wild-type mice but has no effect on LTP in PKM -null mice. [A top, B, C: Adapted from Tsokas et al. (2016). For images of Western blots demonstrating the specificity of the $P K M \zeta$ and $P K C_{1} / \lambda$ antisera please refer to Figure 2 Supplement 1 and Figure 3 Supplement 2, respectively, from that publication].

The blockade of late-LTP and the suppression of activity-dependent PKM $\zeta$ synthesis with bath-applied, recirculating PKM -antisense was also replicated in acute rat hippocampal slices (See Figures 2A, 2B, and S4B from Hsieh et al., 2017). Taken together, these findings suggest that the crucial pool of PKM protein that sustains synaptic potentiation is provided by de novo synthesis in response to tetanization, rather than through the recruitment of pre-existing, basal PKM $\zeta$ that had been synthesized before the tetanus. Thus, the use of antisense ODN to specifically suppress new synthesis of $\mathrm{PKM} \zeta$ without affecting basal levels of the kinase is advantageous over genetic knockdown/knockout not only because it prevents genetic compensation, but because it distinguishes between basal PKM $\zeta$ and the pool of PKM synthesized pool can support late-LTP. A similar argument can be made for the use of acute translational blockade by antisense ODN rather than genetic knockdown/knockout in behavioral experiments designed to elucidate the mechanisms involved in the formation and persistence of long-term memory under physiological conditions in wild-type animals (Tsokas et al., 2016; Hsieh et al., 2017).

Since first described (Tsokas et al., 2016; Hsieh et al., 2017), PKMろ-antisense has been applied acutely on hippocampal slices in two other studies (Dasgupta et al., 2017; Sharma and Sajikumar, 2018) via a peristaltic pump (non-recirculating ACSF). These reports also showed a blockade of LTP.

In our protocol, antisense ODN is delivered by a custom-built recirculation system that perfuses brain slices resting in an "Oslo-type" interface recording chamber with a small $(5 \mathrm{ml})$ recirculating volume of artificial cerebrospinal fluid (ACSF). The system employs the mp6 micropump, a piezoelectric diaphragm pump developed by Bartels Mikrotechnik GmbH (Dortmund, Germany) for the transport of liquids or gases at varying flow rates and/or pressures controlled by an external electronics circuit. For liquids, each $\mathrm{mp} 6$ micropump supplies a maximal flow rate of $5.5 \mathrm{ml} / \mathrm{min}$. With parallel connection of multiple mp6 units the volume flows summate. The mp6 can be controlled by the commercially available $\mathrm{mp}-\mathrm{x}$ controller, or alternatively by the mp6-OEM, both of which are manufactured by Bartels. The mp6-OEM is a small $(10.5 \times 20.5 \times 6 \mathrm{~mm})$ driving circuit capable of generating up to $270 \mathrm{~V}$ peak-to-peak voltage at $100 \mathrm{~Hz}$ frequency from a $5 \mathrm{~V}$ power supply (therefore proper safety measures are required). The OEM controller drives the micropump at adjustable performance and can be integrated into system electronics, a PCB design, or as in the case of this protocol a breadboard.

Each mp6-OEM is intended for operating one mp6 micropump. Therefore, the six $\mathrm{mp}-\mathrm{x}$ controllers that would be required for driving the mp6 arrays used in this protocol would make the cost of using the commercially available controller quite steep-as opposed to using six mp6-OEMs and building a 
custom-made circuit at a small fraction of the price. The mp6-OEM has a built-in interface that allows the user to adapt the adjustable parameters (frequency and amplitude) of the rectangular signal generated by the OEM by the use of external components, such as a circuit consisting of a potential divider and a capacitor, or a microcontroller capable of pulse-width modulation (PWM). For the purposes of this protocol, an Arduino Uno is used with a simple program that performs PWM to control the amplitude and/or the frequency. Using an open source Arduino library and a program provided with this protocol, the user may achieve flow rates between $0.2 \mathrm{ml} / \mathrm{min}$ and $5.5 \mathrm{ml} / \mathrm{min}$ from each $\mathrm{mp} 6$ micropump, appropriate for maintaining brain slices (see Figure 20).

The schematic in Figure 2A represents a simplified version of the circuit that controls the flow rate of the pumps which supply ACSF to the recording chamber (inflow micropumps, controlled by the OEM circuit at the bottom via Microcontroller 2). Figure $2 \mathrm{~A}$ also shows a simplified version of the circuit controlling the suction pumps (outflow micropumps, controlled by the OEM at the top). To achieve laminar flow when the chamber is operated in submersion mode, i.e., during ODN delivery prior to stimulation and recording, slices are perfused on two sides-at the top and the bottom of the mesh. Two micropumps driven by two separate OEMs are therefore used for controlling the inflow: one pump perfuses the top of the mesh, and the other supplies ACSF to the part of the chamber below the mesh (Figures 15A and 15B). A "sandwich" consisting of four mp6 pumps connected in parallel fashion is used to supply the suction that completes the ACSF recirculation circuit (Figure 15C). These four mp6 micropumps operate constantly at maximal flow rate and are therefore controlled by a simpler version of the circuit used for the two inflow micropumps, which does not perform pulse-width modulation.

A separate Arduino Uno microcontroller (Microcontroller 1 ) is used to turn all the mp6 micropumps on/off in a concerted fashion according to inputs received by the ADC and the software driving the electrophysiology experiment. In this manner, the recirculation system can be used in combination with a peristaltic pump via a three-way valve and activated only during drug application.

The first part of this protocol is a description of how to build the electronic circuit that controls the operation and flow rate of the mp6 micropump arrays. The second part provides a detailed hippocampal slice preparation protocol for electrophysiology in interface chambers. The protocol includes modifications of the classic method described in the scientific literature, which, based on our experience, we believe are necessary for making high-quality slices suitable for long electrophysiological recordings and subsequent biochemical and immunocytochemical analysis.

In addition, we provide evidence for the advantage of interface over submersion electrophysiology chambers for long recordings of acute brain slices required for the study of long-term synaptic plasticity (see Note 1). Whereas low-oxygen submersion chambers show unstable baseline synaptic transmission following long-term applications of the zeta inhibitory peptide (ZIP), the interface electrophysiology chambers maintain stable baseline synaptic transmission, as observed after applications of ZIP in vivo (Pastalkova et al., 2006). Thus, because brain slices maintained in interface chambers more closely preserve the in vivo physiological state, they are the preferred method for investigating the long-term synaptic plasticity thought to underlie learning and memory. 


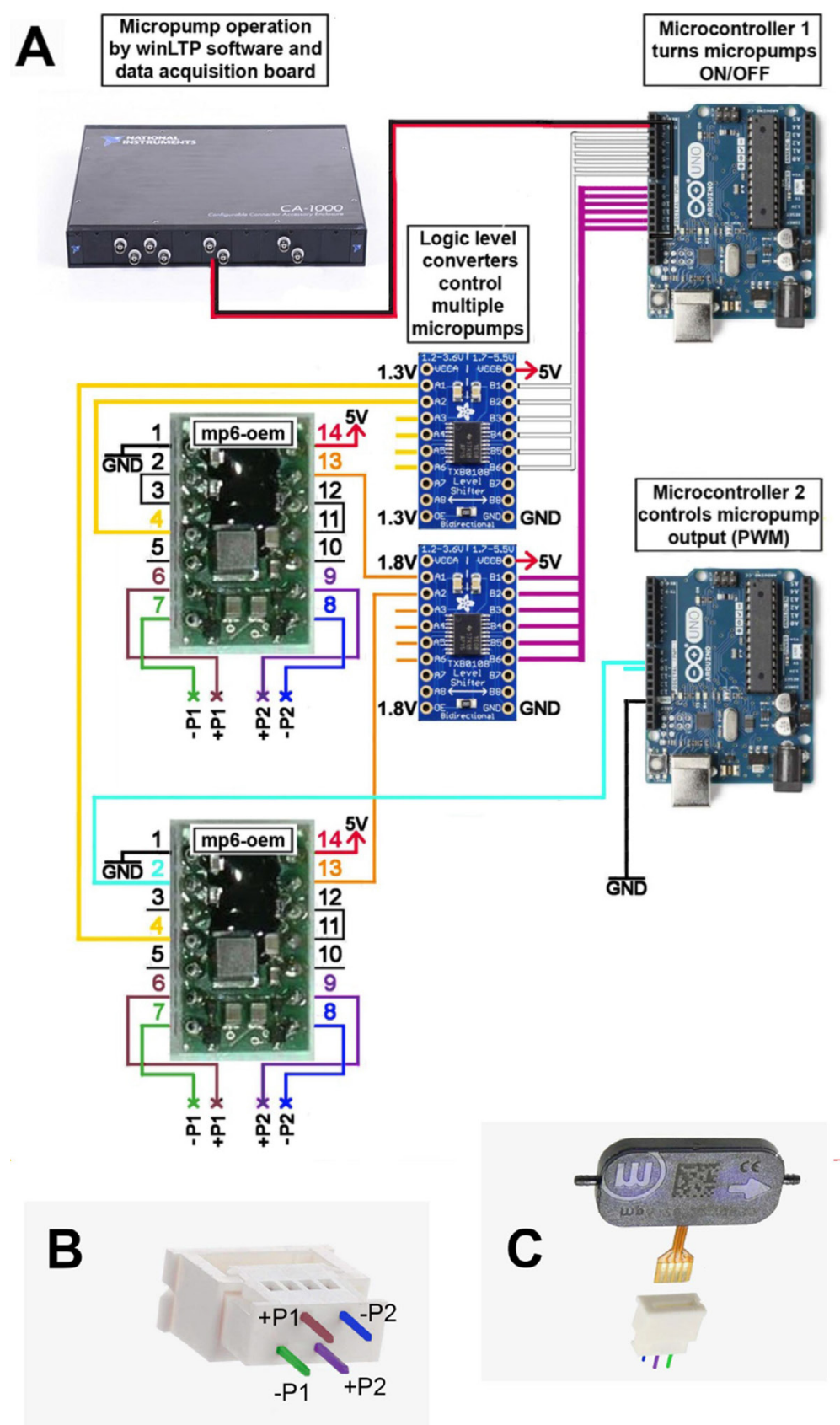

Figure 2. Color-coded schematic of the micropump control circuit and photographs of the micropump Molex connector. A. The cables connecting the different components are color-coded for easy assembly of the circuit; a step-by-step outline is provided in Figures 4-14. B. Color-coded scheme of the connections on the Molex connector. The connections labeled $-\mathrm{P} 1,+\mathrm{P} 1,+\mathrm{P} 2$, and $-\mathrm{P} 2$ should be connected to the four output pins of the OEMs as dictated by the colors. For fast and secure fastening/unfastening of the micopump assemblies, use a $\mathrm{Pi}$ Cobbler Breakout and associated cable. C. Photograph of an mp6 micropump and Molex connector from B. Note that only one side of the micropump has markings (the company logo and micropump serial number). Slide the micropump through the slot, in the orientation shown, and close the Molex component to secure the connection. 


\section{Materials and Reagents}

1. Double-sided adhesive tape (Amazon, model: QK-8285B0134CUFU0_loc)

2. Single Edge Razor Blade (GEM Personna, Electron Microscopy Sciences, catalog number: 71972)

3. Double Edge Razor Blade (Electron Microscopy Sciences, catalog number: 71998)

4. Pyrex Graduated Cylinder 2,000 ml (Corning, VWR, catalog number: 3022-2L)

5. Pyrex Graduated Cylinder $1,000 \mathrm{ml}$ (Corning, VWR, catalog number: $3022-1 \mathrm{~L}$ )

6. Pyrex Graduated Cylinder $100 \mathrm{ml}$ (Corning, VWR, catalog number: 70075-100)

7. Pyrex Culture Petri Dish 90 mm (Corning, VWR, catalog number: 7740)

8. Pyrex Media Storage Bottle, $1 \mathrm{~L}$ (Corning, VWR, catalog number: 1395-1L)

9. Pyrex Gas-Dispersion Tube (Corning, VWR, catalog number: 39533-12C)

10. Pyrex Graduated Beaker, 250 ml (Corning, VWR, catalog number: 1000-250)

11. Pyrex Graduated Beaker, $50 \mathrm{ml}$ (Corning, VWR, catalog number: 1000-50)

12. Pyrex Graduated Beaker, $20 \mathrm{ml}$ (Corning, VWR, catalog number: 1000-20)

13. VWR Erlenmeyer Flask, $250 \mathrm{ml}$ Erlemeyer flask (VWR, catalog number: 75804-646)

14. $15 \mathrm{ml}$ conical tube (VWR, catalog number: 62406-200)

15. Scalpel Handle \#3 (Fine Science Tools, catalog number: 10003-12)

16. Scalpel Blade \#10 (Fine Science Tools, catalog number: 10010-00)

17. Surgical Scissors-ToughCut (Fine Science Tools, catalog number: 14054-13)

18. Extra Fine Bonn Scissors (Fine Science Tools, catalog number: 14084-08)

19. Friedman-Pearson Rongeurs (Fine Science Tools, catalog number: 16221-14)

20. Spatula (VWR, catalog number: 82027-490)

21. Ellipso-spoon Spatula ((VWR, catalog number: 100493-952)

22. Camel Hair Brush \#1 (Ted Pella, Inc., catalog number: 11859)

23. Insect pin (Fine Science Tools, catalog number: 26000-50)

24. Whatman Grade 5 Filter Paper 55 mm (Whatman, VWR, catalog number: 1005 055)

25. Whatman Grade 5 Filter Paper 90 mm (Whatman, VWR, catalog number: 1005 090)

26. Transfer Pipets (Fisherbrand, Fisher Scientific, catalog number: 13-711-7M)

27. Tubing Extension with $1.3 \mathrm{~mm}$ I.D. (Cole Parmer, catalog number: SK-95809-32)

28. Tygon Tubing, $1.6 \mathrm{~mm}$ I.D. (Cole Parmer, catalog number: SK-06407-33)

29. Teflon/PTFE Tubing, 1.6 mm I.D. (Cole Parmer, catalog number: SK-95231-00)

30. Three-way valves (Cole Parmer, catalog number: SK-30600-02)

31. Female and male gold-plated Pins (Fine Science Tools, catalog numbers: 19003-01 and 19-003-00)

32. Calcium Chloride Solution, $1 \mathrm{M}\left(\mathrm{CaCl}_{2}\right)$ (Teknova, catalog number: $\mathrm{C} 0477$, room temperature)

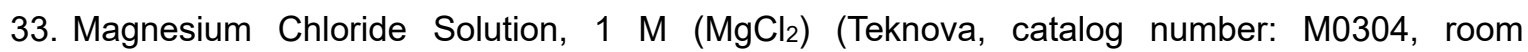
temperature)

34. Magnesium Sulfate Solution, $1 \mathrm{M}\left(\mathrm{MgSO}_{4}\right)$ (Teknova, catalog number: $\mathrm{M} 3003$, room 
temperature)

35. Potassium Chloride (KCl) (Fisher Scientific, catalog number: P9541-1KG, room temperature)

36. Sodium Bicarbonate $\left(\mathrm{NaHCO}_{3}\right)$ (Sigma-Aldrich, catalog number: S5761-500G, room temperature)

37. Sodium Chloride ( $\mathrm{NaCl}$ ) (Sigma-Aldrich, catalog number: S271-3, room temperature)

38. Sodium Phosphate Monobasic $\left(\mathrm{NaH}_{2} \mathrm{PO}_{4}\right)$ (Sigma-Aldrich, catalog number: S5011-500G, room temperature)

39. D-(+)-Glucose (Sigma-Aldrich, catalog number: G7528-1KG, room temperature)

40. Isothesia (Isoflurane) Solution $\left(\mathrm{C}_{102} \mathrm{ClF}_{5} \mathrm{O}\right)$ (Henry Schein Animal Health, catalog number: 029404, room temperature)

41. Antisense and Scrambled ODN (reverse phase cartridge-purified) with phosphorothioate linkages 5'-3' on three terminal bases at each end to protect against nuclease degradation, as per Tsokas et al. (2016), Hsieh et al. (2017) (Gene Link, Hawthorne, NY, $4{ }^{\circ} \mathrm{C}$ )

42. $100 \%$ Oxygen (TW Smith)

43. $95 \%$ Oxygen- $5 \%$ Carbon Dioxide (TW Smith)

44. 10x Stock Dissection ACSF Buffer (see Recipes)

45. 10x Stock Recording ACSF Buffer (see Recipes)

46. 1x Dissection ACSF Buffer (see Recipes)

47. 1x Recording ACSF Buffer (see Recipes)

\section{Equipment}

1. $4{ }^{\circ} \mathrm{C}$ cold room

2. $-70{ }^{\circ} \mathrm{C}$ freezer: Thermo Scientific Forma 88000 Series $-86{ }^{\circ} \mathrm{C}$ (Thermo Scientific, model: 88600D)

3. Water bath: Fisherbrand Isotemp Digital-Control Water Bath Model 202 (Fisher Scientific, model: $15-462-2 Q$ )

4. Corning Round Ice Bucket with Lid, 4 L (Fisher Scientific, catalog number: 07-210-123)

5. "Oslo-type" Interface Brain Slice Recording Chamber (Fine Science Tools, catalog number: 21000-02)

6. Warner TC-344C Dual Channel Temperature Controller (Warner Instruments, catalog number: 64-2401)

7. Dissection Binocular Stereo Zoom Microscope with Boom Stand (Nikon, Morrell Instrument Co., catalog number: SMZ800N)

8. Fiber Optic Light Source (Dolan-Jenner MILEDUSB1 MI-LED-US-B1)

9. Dual Gooseneck Fiber Optic Assembly (Dolan-Jenner EEG3736 002144113036)

10. Neuroprobe Amplifier, Model 1600 (A-M Systems, catalog number: 680100)

11. Model 1600 Headstage (A-M Systems, catalog number: 681500)

12. ADC Connector Box (National Instruments, catalog number: BNC-2090A) 
13. ADC PCI Bus Card (National Instruments, catalog number: PCle-6323)

14. Dell Optiplex 3040 (Amazon, catalog number: B01E8QRSAG)

15. ISO-flex Stimulator (AMPI, catalog number: ISO-flex)

16. Narishige MX-2 Micromanipulator

17. Narishige MM-3 Micromanipulators

18. Flaming/Brown Pipet Puller (Sutter Instruments, catalog number: P-97)

19. Mcllwain Tissue Chopper (Mcllwain Lab, Ted Pella, Inc., catalog number: 10180)

20. Plastic Disc (Ted Pella, Inc., catalog number: 10180-01)

21. Rodent Guillotine (WPI, World Precision Instruments, catalog number: DCAP)

22. Isoflurane Vaporizer (VSS, catalog number: 300 Series)

23. Anesthesia Induction Chamber (Leica Biosystems, catalog number: 39481051/3)

24. Six mp6-OEM controllers (Mp6-oem, Bartels Mikrotechnik GmbH, Servoflo catalog number: Mp6-oem)

25. Six mp6 micropumps (mp6, Bartels Mikrotechnik $\mathrm{GmbH}$, Servoflo catalog number: $\mathrm{mp6}$ )

26. Six Passive Check Valves mp-cv (Bartels Mikrotechnik, Servoflo, catalog number: mp-cv)

27. Six FCC connectors (Molex; Digi-Key, catalog number: 0039532045)

28. Two Arduino Uno Microcontrollers (Adafruit Industries, catalog number: 782-A000066)

29. Two 8-channel Bi-directional Logic Level Converters (Adafruit Industries, catalog number: TXB0108)

30. Assembled Pi Cobbler Breakout Board + 26-pin Ribbon Cable for Raspberry Pi Models A \& B (Adafruit, catalog number: 914)

31. Shield stacking headers for Arduino (R3 Compatible) (Adafruit, catalog number: 85)

32. Male/male Jumper Wires (Adafruit, catalog numbers: 758,1956 )

33. Jumper Wire Kit-pre-cut and bent in right angles, 700 pcs (Sparkfun Electronics, catalog number: PRT-14671)

34. MC001 Alpha Wire Multi-Conductor Cables (Mouser, catalog number: 602-1102-100)

35. WBU-206 Breadboard $31 \mathrm{~mm} \times 175 \mathrm{~mm} \times 230 \mathrm{~mm}$ (Newark Electronics, catalog number: 18M7115); Alternative: Digilent 340-002-1 (Digi-Key, catalog number 1286-1220-ND)

36. 10K-Ohm 15-Turn Cermet Potentiometer/Trimmer (RadioShack, catalog number: 2710343)

37. RS Pro 1440976, AC to DC Desktop Power Supply, 5 VDC, 7.5 A (Allied Electronics, catalog number: 71259700)

38. SPST Push On/Off Switch (RadioShack, catalog number: 2750011)

39. Six Y-shape tubing connectors, barbed (Servoflo, catalog number: $\mathrm{mp}-\mathrm{y}$ )

40. Heat Shrink Tubing (Mouser, catalog number: 650-VER332SP)

41. Weller WTCPT Soldering Station (Digi-Key, catalog number: WTCPT-ND)

42. Solder (Digi-Key, catalog number: KE1106-ND)

43. Heat gun: AlphaWire Fit Gun-1 (Digi-Key, catalog number: FGUN1NC032-ND)

44. Multimeter Fluke 177 (Digi-Key, catalog number: 614-1020-ND)

45. USB cables (Amazon, ASIN: B003ZZH2U8) 
46. Nine custom-made plexiglass spacers (MSC Industrial Supply, catalog number: 63388953)

47. Six custom-made Cork pad spacers (Cork Pad sheet from Amazon, ASIN: B001ACMBO0)

48. Flathead 2-56 3/4 inch screws: (MSC Industrial Supply, catalog number: 40914715)

49. Copper 33 Gage, 0.011 Inch Wire Diameter, 16 x 16 Mesh (MSC Industrial Supply, catalog number: 52427291)

50. Velcro 1" Wide Adhesive Backed Hook \& Loop Roll (MSC Industrial Supply, catalog number: 67127480)

51. Clamps (Fisher Scientific, 05-769-7Q; S13743; 02-215-466; 02-300-206)

52. Optional: Dissolved Oxygen Kit (Atlas Scientific, Atlas Scientific, catalog number: KIT-106)

\section{Software}

1. winLTP (WinLTP Ltd. and The University of Bristol, https://www.winltp.com)

2. Arduino Software (IDE) (Arduino, https://www.arduino.cc/en/Main/Software)

3. Atlas Scientific Dissolved Oxygen OEM sample code

(https://www.atlas-scientific.com/ files/code/oem-do-sample-code.pdf)

\section{Procedure}

\section{Part I: ACSF Recirculation System Assembly}

A. Assembly of the Micropump Control Circuit

For a simplified schematic with color-coded cables refer to Figure 2A. For detailed, step-by step photos of the assembly of the circuit, consult Figures 4-14. For a table listing all the connections required for the mp6 micropump control circuit, see Figure 3. 
Please cite this article as: Tsokas et. al., (2019). Antisense Oligodeoxynucleotide Perfusion Blocks Gene Expression of Synaptic Plasticity-related

\begin{tabular}{|c|c|c|c|c|c|}
\hline Component & Connection & Component & Connection & Component & Connection \\
\hline Potentiometer 1 & T2B25, T2C27, T2B30 & & T1 T2 & White Cable 1 & ARDUINO1 T2 \\
\hline Potentiometer 2 & $\mathrm{~T} 2 \mathrm{C} 33, \mathrm{~T} 2 \mathrm{~B} 36, \mathrm{~T} 2 \mathrm{C} 38$ & & T2 & White Cable 2 & ARDUINO1 T2 \\
\hline \multicolumn{2}{|c|}{ logic level converter $1 \mathrm{~T} 2 \mathrm{E} 7-\mathrm{E} 16 \mathrm{~T} 2 \mathrm{H} 7-\mathrm{H} 16$} & & T2 & White Cable 3 & ARDUINO1 T2 10 \\
\hline \multicolumn{2}{|c|}{ logic level converter 2 T2E47-E56T2H47-H56 } & & $\begin{array}{ll}\text { T1 } & \text { T2 }\end{array}$ & White Cable 4 & ARDUINO1 T2 11 \\
\hline mp6-OEM 1 & T1E1-7T1F1-7 & & T1 & White Cable 5 & ARDUINO1 T2 12 \\
\hline mp6-OEM 2 & T1E9-15T1F9-15 & & T1 & White Cable 6 & ARDUINO1 T2 13 \\
\hline mp6-OEM 3 & T1E17-23T1F17-23 & & & & \\
\hline mp6-OEM 4 & T1E41-47T1F41-47 & Orange Cable 1 & $\mathrm{T1} J 2 \mathrm{~T} 2 \mathrm{D} 48$ & Magenta Cable 1 & ARDUINO1 8 T2 48 \\
\hline mp6-OEM 5 & T1E49-55T1F49-55 & Orange Cable 2 & T1」10T2D49 & Magenta Cable 2 & ARDUINO1 9 T2 49 \\
\hline mp6-OEM 6 & T1E57-63T1F57-63 & Orange Cable 3 & T1」18T2D50 & Magenta Cable 3 & ARDUINO110T2 50 \\
\hline \multirow[t]{2}{*}{ Breakout Board } & T1D25-37T1H25-37 & Orange Cable 4 & T1」42T2D51 & Magenta Cable 4 & ARDUINO1 11 T2 51 \\
\hline & & Orange Cable 5 & T1J50T2D52 & Magenta Cable 5 & ARDUINO1 12 T2 \\
\hline Red Cable 1 (+) & T1J1H1B15 & Orange Cable 6 & T1J58T2D53 & Magenta Cable 6 & ARDUINO1 13 T2 \\
\hline Red Cable 2 (+) & V2B2H1B18 & & & & \\
\hline Red Cable 3 (+) & V3B2H1B34 & Brown Cable 1 & T1A6T1A25 & Purple Cable 1 & T1J6T1J25 \\
\hline Red Cable 4 (+) & T119V2B6 & Brown Cable 2 & T1A14T1A27 & Purple Cable 2 & T1J14T1J27 \\
\hline Red Cable 5 (+) & T1117V2B13 & Brown Cable 3 & T1A22T1A29 & Purple Cable 3 & T1J22T1J29 \\
\hline Red Cable 6 (+) & T1/41V2B33 & Brown Cable 4 & T1A46T1A31 & Purple Cable 4 & T1J46T1J31 \\
\hline Red Cable 7 (+) & T1/49V2B40 & Brown Cable 5 & T1A54T1A33 & Purple Cable 5 & T1J54T1J33 \\
\hline Red Cable 8 (+) & T1157V2B46 & Brown Cable 6 & T1A62T1A35 & Purple Cable 6 & T1J62T1J35 \\
\hline Red Cable 9 (+) & V2B20T2A25 & & & & \\
\hline Red Cable 10 (+) & V2B30T2A38 & Green Cable 1 & T1A7T1A26 & Blue Cable 1 & T1J7T1J26 \\
\hline Red Cable 11 (+) & T217V3B5 & Green Cable 2 & T1A15T1A28 & Blue Cable 2 & T1J15T1J28 \\
\hline \multirow[t]{2}{*}{ Red Cable $12(+)$} & T2147V3B38 & Green Cable 3 & T1А23T1А30 & Blue Cable 3 & T1J23T1J30 \\
\hline & & Green Cable 4 & T1A47T1A32 & Blue Cable 4 & T1J47T1J32 \\
\hline Black 1 (Ground) & V1A2H1A2 & Green Cable 5 & T1A55T1A34 & Blue Cable 5 & T1J55T1J34 \\
\hline Black 2 (Ground) & V1A6T1A9 & Green Cable 6 & T1А63T1А36 & Blue Cable 6 & T1J63T1J36 \\
\hline Black 3 (Ground) & V1A13H1A17 & & & & \\
\hline Black 4 (Ground) & V1A33H1A41 & U connector 1 & T1A2T1A3 & yan Cable 1 & ARDUINO2 T1 50 \\
\hline Black 5 (Ground) & V1A40H1A49 & U connector 2 & T1A10T1A11 & Cyan Cable 2 & ARDUINO2 T1 \\
\hline Black 6 (Ground) & V1A46H1A57 & U connector 3 & T1A18T1A19 & & \\
\hline Black 7 (Ground) & T1B1H1A6 & U connector 4 & T1A42T1A43 & Grey Cable 1 & T2D7T2E27 \\
\hline Black 8 (Ground) & V2A2H1A17 & U connector 5 & T1J3T1J4 & Grey Cable 2 & T2D16T2D27 \\
\hline Black 9 (Ground) & V2A24T2A30 & U connector 6 & T1J11T1J12 & Grey Cable 3 & T2D36T2D47 \\
\hline Black 10 (Ground) & V2A26T2A33 & U connector 7 & T1J19T1J20 & Grey Cable 4 & T2E36T2D56 \\
\hline Black 11 (Ground) & V3A1H1A32 & U connector 8 & T1J43T1J44 & & \\
\hline Black 12 (Ground) & T2J16V3A12 & U connector 9 & T1J51T1J52 & & \\
\hline Black 13 (Ground) & T2156V3A46 & U connector 10 & т1J59T1J60 & & \\
\hline
\end{tabular}

T1: Teminal Strip 1

T2: Teminal Strip 2

H1: Horizontal Power Distribution Bus 1

V1: Vertical Power Distribution Bus 1

V2: Vertical Power Distribution Bus 2

V3: Vertical Power Distribution Bus 3

Figure 3. Table listing all the breadboard connections required for the mp6 micropump control circuit 


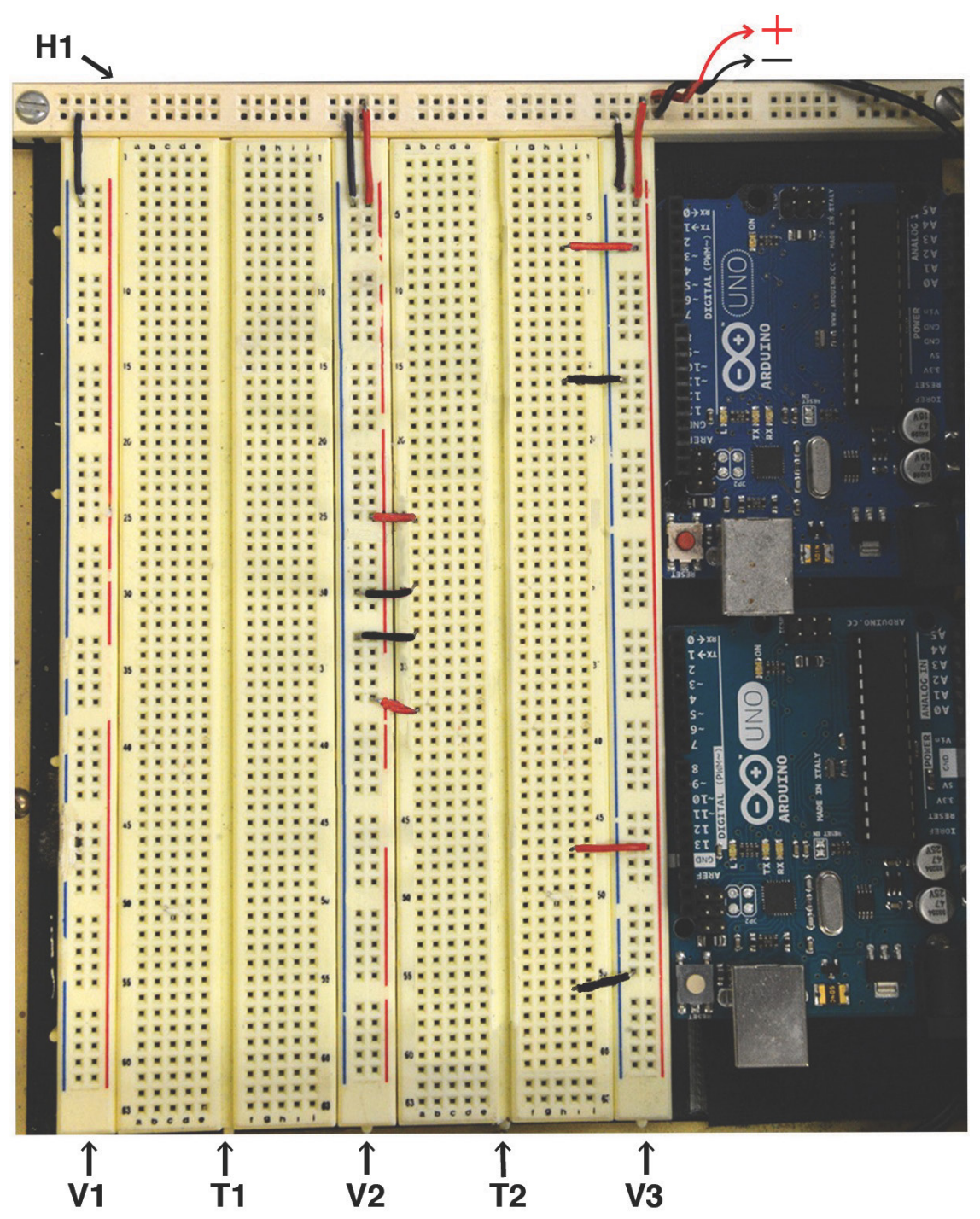

Figure 4. Steps $1-4$ of the assembly of the mp6 micropump control circuit. See text for details.

1. To fit all the necessary components, a breadboard with 3 terminal strips and 63 rows of 10 tie points per terminal strip is required (Figure 4). Such breadboards include the Digilent 340-002-1 or the Wisher WBU-206. Each of these has 5 power distribution buses and 3 terminal strips. Remove (unscrew) the rightmost distribution bus and the adjacent terminal strip.

2. Attach with screws or Velcro pads the two Arduinos-ideally in a staggered fashion to allow easy access to the two USB ports, as shown in Figure 4.

3. Connect the 5 Volt DC Power Supply to the horizontal distribution bus of the breadboard (Figure 4, designated by the red "plus" and the black "minus" signs). Include a simple toggle SPST push button "master switch" (not shown), for switching the power supply to the circuit.

4. Connect the power and ground of all vertical distribution buses to $5 \mathrm{~V}$ and ground, respectively, of the horizontal distribution bus (Figure 4) 


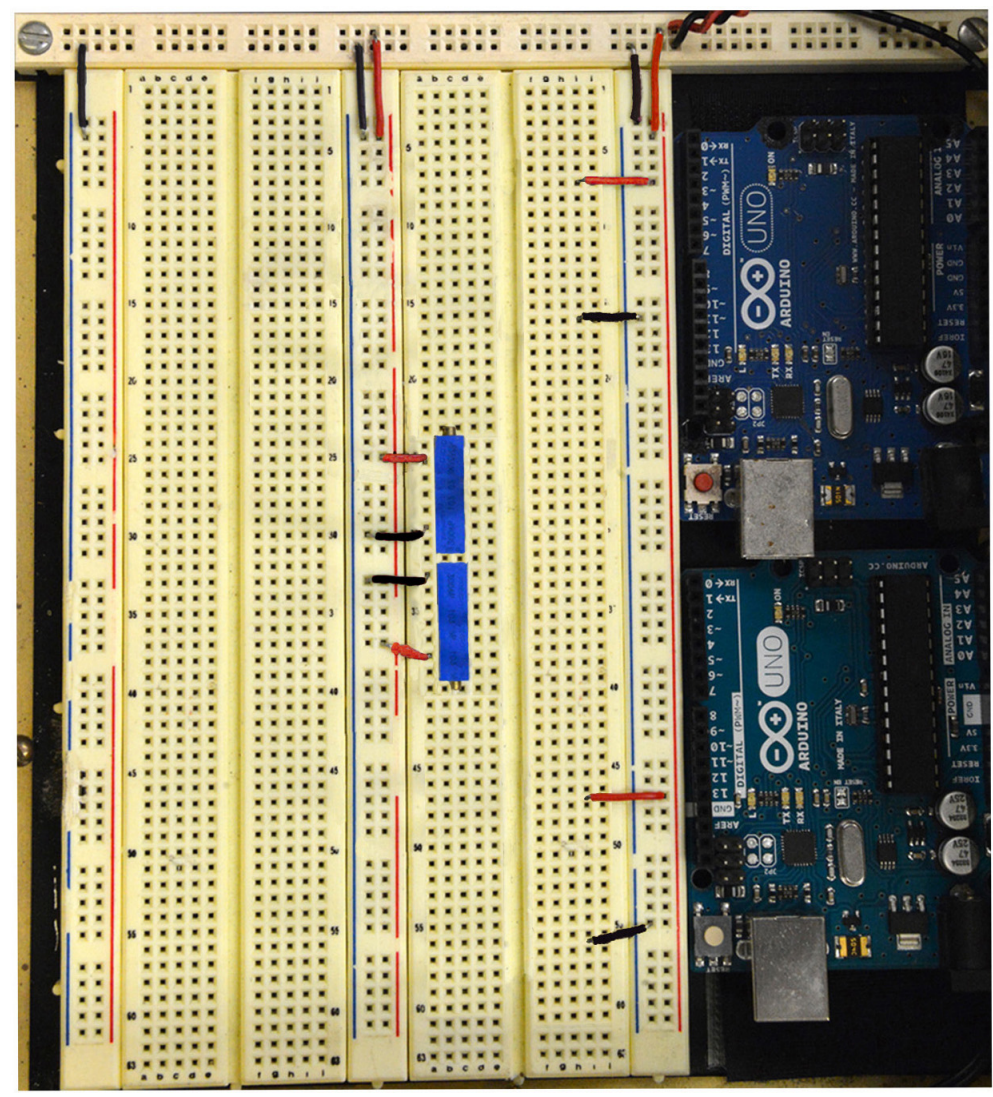

Figure 5. Steps 5-6 of the assembly of the mp6 micropump control circuit. See text for details.

5. On the middle (now rightmost) terminal strip attach the two 10K-Ohm potentiometers, and connect them to power and ground, as shown in Figure 5.

Note: The screws that rotate the wiper and vary the resistance in each potentiometer should be facing away from each other, therefore allowing enough clearance for the mini screwdriver that will be used to make adjustments in Step 6.

6. Using a mini screwdriver, adjust voltage to get $1.3 \mathrm{~V}$ across the wiper of the top potentiometer and $1.8 \mathrm{~V}$ across the bottom.

Note: For safety, you should disconnect the power supply when proceeding with the next steps of the protocol. 




Figure 6. Steps 7-8 of the assembly of the mp6 micropump control circuit. See text for details.

7. On the terminal strip that includes the two potentiometers also install the two 8-channel logic level converters (Figure 6). Connect VCCB on each logic level converter to $5 \mathrm{~V}$ and GND to ground (Figure 6; also refer to Figure 2A for pinout diagram and voltage information).

8. Connect VCCA and OE on the top logic level converter to $1.3 \mathrm{~V}$ and on the bottom converter to $1.8 \vee$ (see gray jumper wires in Figures 6; also refer to Figure $2 \mathrm{~A}$ for voltage and pin information).

9. Attach the 26-pin Assembled Pi Cobbler Breakout Board. Use the shield stacking headers to elevate the Breakout Board, and therefore allow enough clearance for the third and fourth mp6-OEM controllers that will be attached next (Step 10) and are directly adjacent to the Breakout Board (see Figure 15D). 


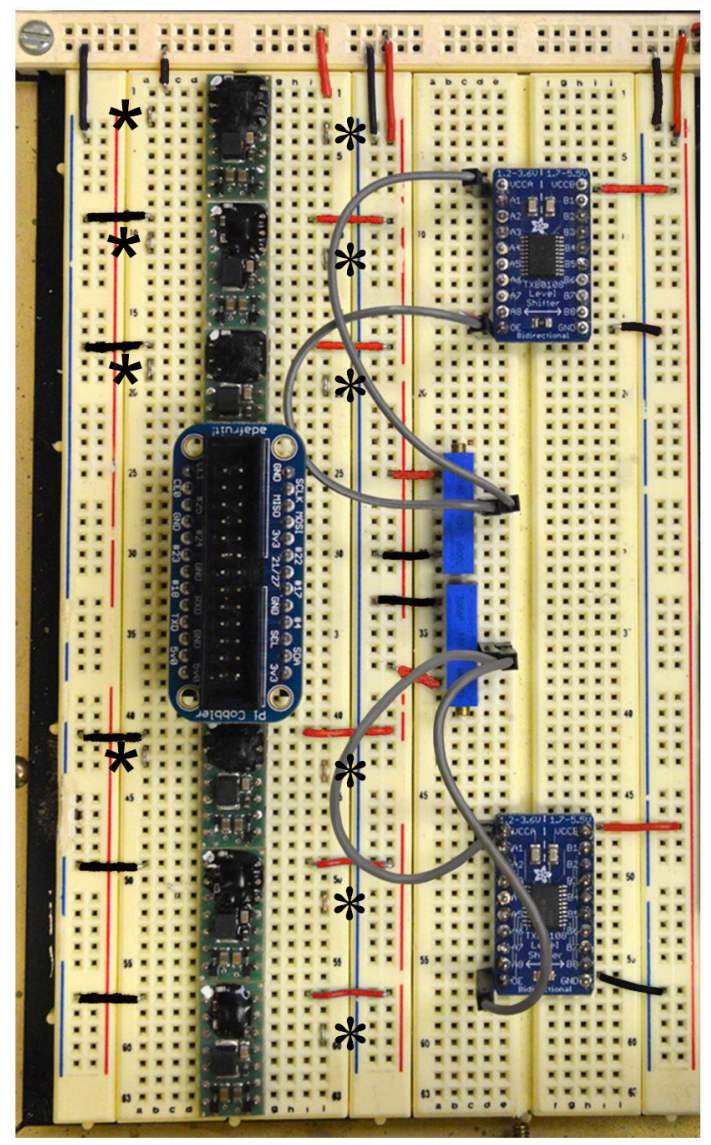

Figure 7. Steps 9-14 of the assembly of the mp6 micropump control circuit. See text for details.

10. Connect the six mp6-OEM controllers to the leftmost terminal strip of the breadboard as shown in Figure 7 (also refer to Figure 2A).

Note: The bottom two mp6-OEM controllers will supply the inflow lines (perfusing the top and bottom sides of the mesh) of the bath of the interface chamber, and their flow rate is adjustable by the bottom Arduino Uno, which is connected to Pin 2 (Cyan, added in Step 22) (Figure 2, and Figures $15 A$ and 15B). The top four OEMs are connected to the four-pump array that supplies the suction (Figure 15C), and their flow rate is constant (set at maximal). For these OEMs, Pin 2 and Pin 3 are shorted and do not receive any input from the bottom Arduino Uno (Figure 2A). Also notice that in all six of the OEMs Pin 5 and Pin 10 are unused.

11. Short Pins 11 and 12 on all six mp6-OEMs, using U-shaped loops made out of cut jumper wires, long enough to connect two contacts on adjacent breadboard rows (see six-pointed asterisks in Figure 7; refer to Figure 2A for numbering of pins).

12. Similarly, short Pins 2 and 3 of the top four OEMs (see five-pointed asterisks in Figure 7; refer to Figure $2 \mathrm{~A}$ for numbering of pins).

13. Connect the ground (Black) to Pin 1, marked with a white spot of all six mp6-OEMs (Figure 7; refer to Figure $2 \mathrm{~A}$ for numbering of pins). 
Please cite this article as: Tsokas et. al., (2019). Antisense Oligodeoxynucleotide Perfusion Blocks Gene Expression of Synaptic Plasticity-related

14. Connect $5 \mathrm{~V}$ (Red) to Pin 14 of all six mp6-OEMs, as shown in Figure 7 (refer to Figure 2A for numbering of pins).

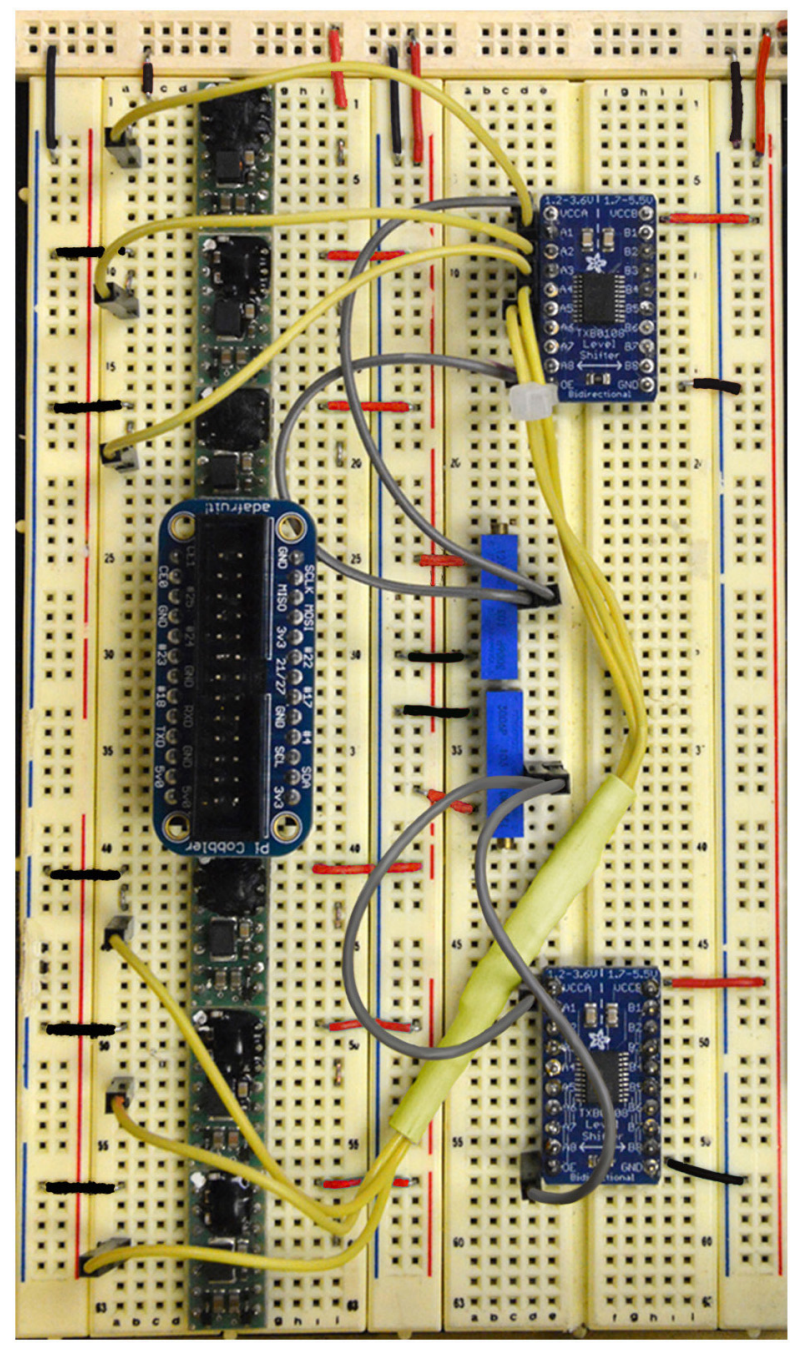

Figure 8. Step 15 of the assembly of the mp6 micropump control circuit. See text for details.

15. Connect 1.3 V (Yellow), from $A 1, A 2, A 3, A 4, A 5, A 6$ of the top logic level converter, to Pin 4 of all six mp6-OEMs (Figure 8; only two such connections are shown in the schematic of Figure $2 A)$. 


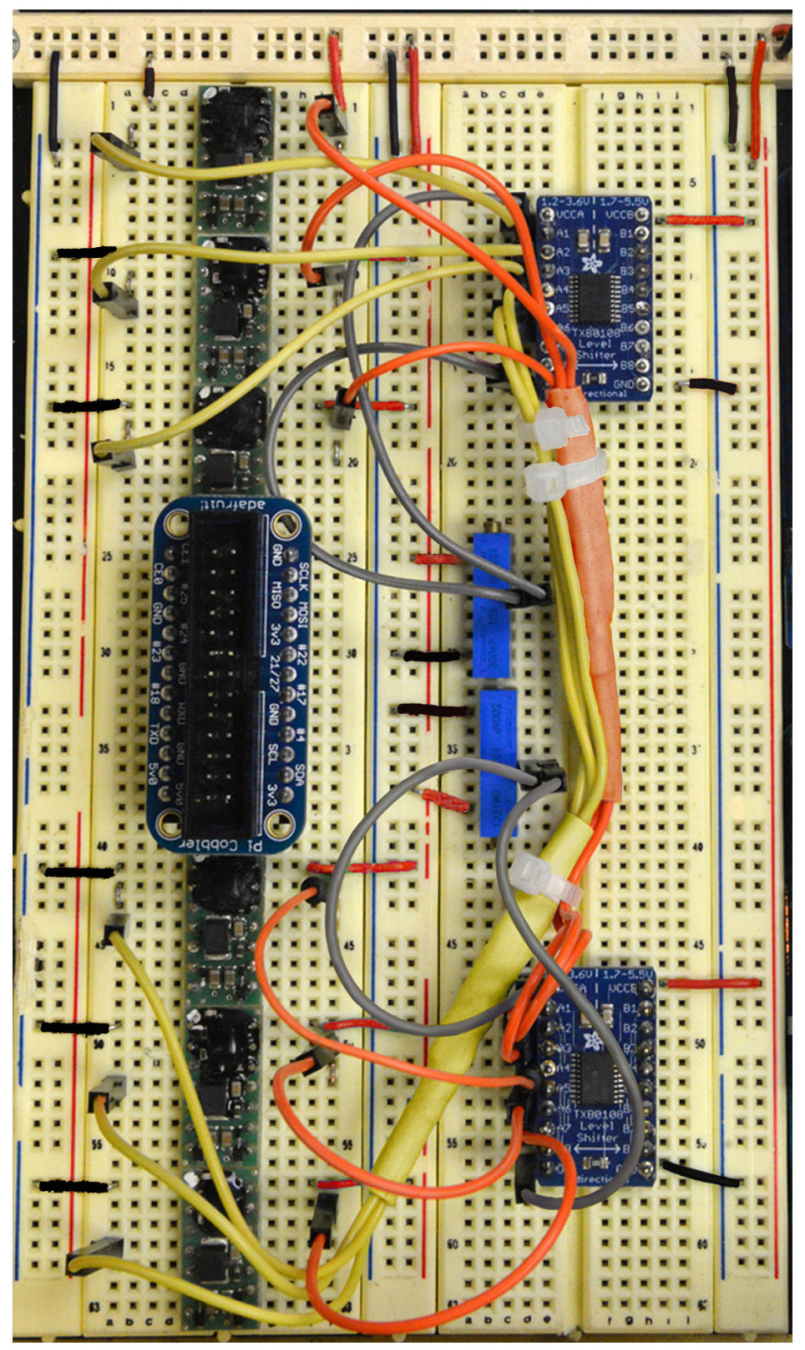

Figure 9. Step 16 of the assembly of the mp6 micropump control circuit. See text for details.

16. Connect 1.8 V (Orange), from $A 1, A 2, A 3, A 4, A 5, A 6$ of the bottom logic level converter, to Pin 13 of all six mp6-OEMs. (Figure 9; only two such connections are shown in the schematic of Figure 2A). 




Figure 10. Steps 17-18 of the assembly of the mp6 micropump control circuit. See text for details.

17. Connect Pin 6 (Brown) to Pins Left 1, 3, 5, 7, 9, 11 of the Assembled Pi Cobbler Breakout (Figure 10).

18. Connect Pin 7 (Green) to Pins Left 2, 4, 6, 8, 10, 12 of the Assembled Pi Cobbler Breakout (Figure 10). 


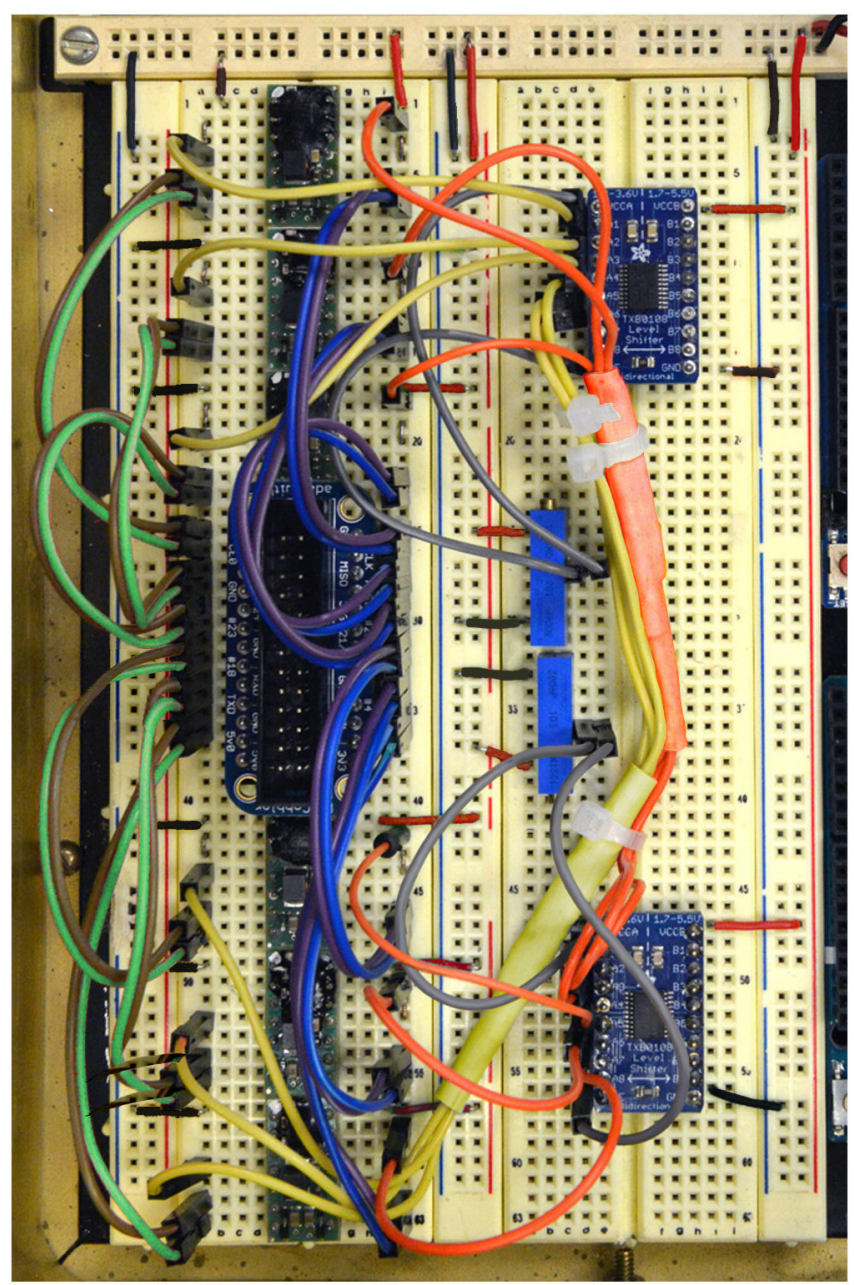

Figure 11. Steps 19-20 of the assembly of the mp6 micropump control circuit. See text for details.

19. Connect Pin 8 (Blue) to Pins Right 2, 4, 6, 8, 10, 12 of the Assembled Pi Cobbler Breakout (Figure 11).

20. Connect Pin 9 (Purple) to Pins Left 1, 3, 5, 7, 9, 11 of the Assembled Pi Cobbler Breakout (Figure 11). 
Please cite this article as: Tsokas et. al., (2019). Antisense Oligodeoxynucleotide Perfusion Blocks Gene Expression of Synaptic Plasticity-related



Figure 12. Step 21 of the assembly of the mp6 micropump control circuit. See text for details.

21. Connect Inputs B1, B2, B3, B4, B5, B6 of the top logic level converter to Digital Pins 2, 3, 4, 5, 6, 7, respectively, of the top Arduino Uno, as shown in Figure 12 (White cables). 


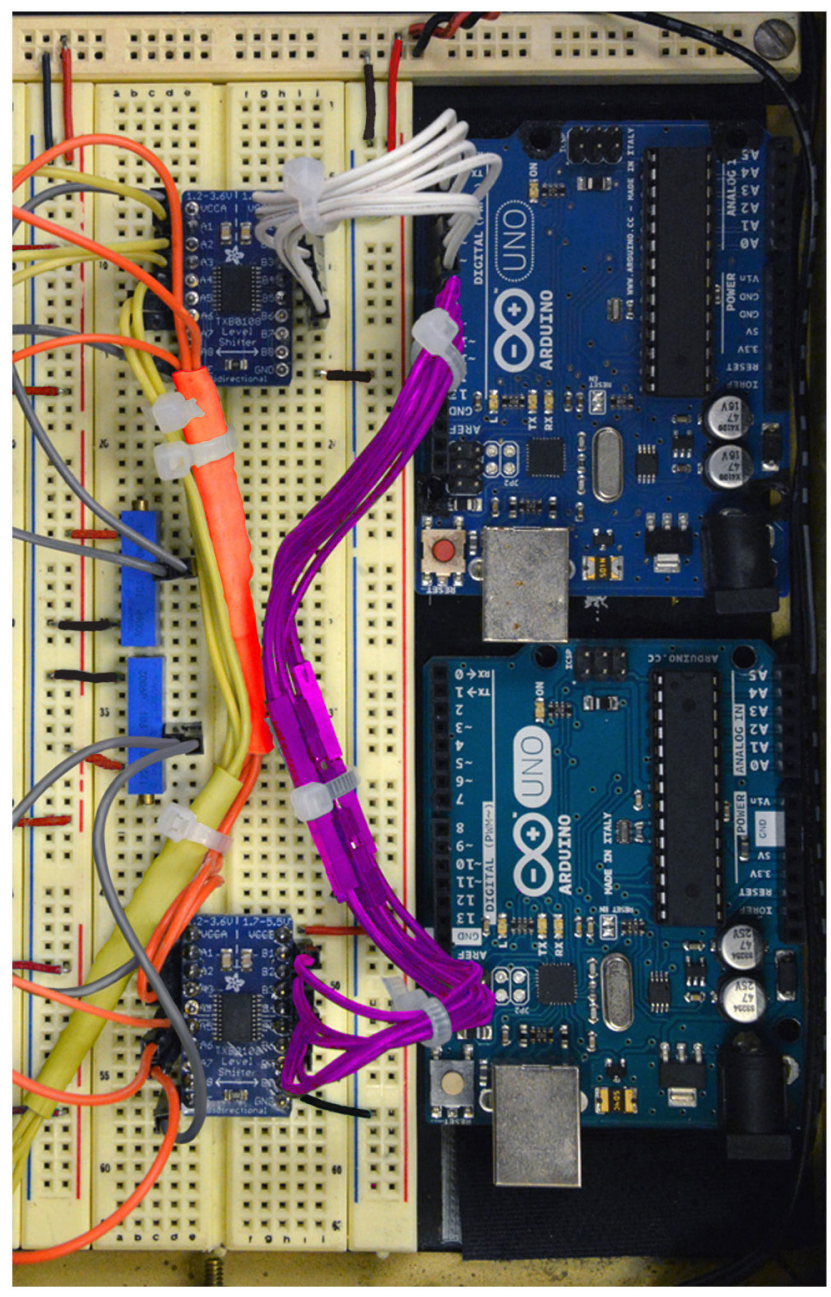

Figure 13. Step 22 of the assembly of the mp6 micropump control circuit. See text for details.

22. Connect Inputs B1, B2, B3, B4, B5, B6 of the bottom logic level converter to Digital Pins 8, 9 , $10,11,12,13$, respectively, of the top Arduino Uno, as shown in Figure 13 (Magenta cables). 




Figure 14. Step 23 and complete overview of the assembly of the mp6 micropump control circuit. See text for details.

23. Connect Outputs 9 and 10 (PWM0 and PWM1) of the bottom Arduino Uno to Pin 2 (Cyan) of the bottom two OEMs (Figure 14).

24. Connect one of the Digital outputs of the ADC to TX 1 and GDN of the top Arduino Uno (Figure 2A). This connection will turn on and off the recirculation perfusion controlled by the mp6 pumps, as directed by the winLTP Program.

25. Connect the two Arduino Uno units to the computer, using USB connection.

26. Connect the GDN of the bottom Arduino to the central ground of the electrophysiology rig. (Figure 2A. The top Arduino is grounded via the ADC ground-see Step 24).

27. Copy and load into the top Arduino controlling all six micropumps (Microcontroller 1) the program shown in Figure 18.

28. Copy and load into the bottom Arduino controlling the two inflow micropumps (Microcontroller 2) the program shown in Figure 19.

B. Assembly of the mp6 micropump array (see reference 29)

1. Assemble the six cables connecting the six Molex connectors (one per mp6 micropump) to the Breakout Board 26-pin ribbon cable, as shown in Figures 2B and 15E. The color scheme of Figures $2 \mathrm{~B}$ and $2 \mathrm{C}$ serves as a guide. Use four male gold-plated pins and a 32AWG 4-wire multi-conductor cable (e.g., the MC001 Alpha Wire Multi-Conductor Cable) to connect the four 
pins of the Molex connector to the ribbon cable. Each Molex connector and associated multicolor cable will be inserted into four sockets of the ribbon cable (wire arrangement, clockwise from top left socket: brown, purple, blue, green; repeat for all six Molex connectors). Only $24(6 \times 4)$ out of the 26 sockets of the ribbon cable will be used.

Note: Disregard the colors of the Alpha Wire multicolor cables in Figures 15A, 15B, 15C, 15E and $15 F$, which are unrelated to the color scheme of Figure $2 B$.

2. Position both components as indicated in Figure $2 \mathrm{C}$, the $\mathrm{mp} 6 / \mathrm{mp} 6$-pp facing upwards (with its company logo and serial number markings visible from above), and the Molex connector with the four small openings facing down. Then slide the mp6/mp6-pp flex into the Molex connector. Clamp the Molex connector to complete the connection between both components.

3. Manufacture three custom-made plexiglass spacers similar to the ones shown in Figures 15A and 15B. Also prepare cork pads cut to size in order to compensate for differences in the thickness of the micropump and the Molex connectors.

4. Make an assembly consisting of two mp6 micropumps as shown in Figures $15 \mathrm{~A}$ (front) and $15 \mathrm{~B}$ (side) as follows: First, glue the marked side of micropump 1 (mp6-1) on the plexiglass spacer using double-sided adhesive tape. Glue cork pads to the unmarked side of the first micropump. The order of parts in the resulting component is: plexiglass/mp6-1/cork.

5. Repeat these steps for micropump 2 (mp6-2), but in the opposite order, i.e., with the cork pad glued to marked side and the plexiglass spacer on the unmarked. The order of parts in the resulting component is: cork/mp6-2/plexiglass.

6. Build a four mp6 micropump assembly (Figure 15C) consisting of the two plexiglass spacer/mp6/cork pad components, by placing the third (unglued) plexiglass spacer in between, so that order of parts in the completed array is:

plexiglass/mp6-1/cork/plexiglass/cork/mp6-2/plexiglass.

7. The resulting assembly can be held together either with pieces of double-sided adhesive tape, or by a clamp, or with long screws that pass through drilled holes into the plexiglass spacers. In the latter case, make sure to tap threads into the holes of only one out of the three spacers.

8. Make mini-Faraday cages out of copper wire mesh (Figure 15F) to allow the elimination of the noise generated by the piezoelectric micropumps (see Note 3). Ground the mini Faraday cages on the main ground of the airtable.

9. The completed assemblies consist of either two or four mp6 micropumps (Figure 15F). As discussed above, four pumps connected in parallel are required for the suction, and two pumps with independent inlets and outlets perfuse the top and bottom of the hippocampal slice, from both sides of the mesh in the recording chamber. 
A

B

C


F

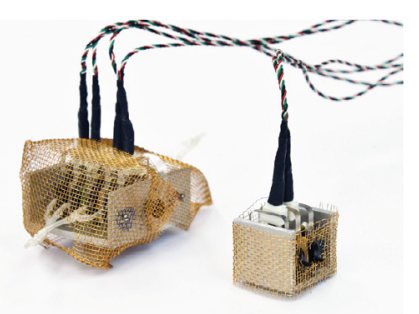

Figure 15. Different views of the assembled micropump arrays and associated components. A and B. Two mp6 micropumps are stacked in parallel connection, which causes their volume flows to summate. Each such "sandwich" array consists of three custom-made plexiglass panels, one of which is threaded so that screws can hold the assembly together. Cork pads cut to size allow for precise contact of different surfaces. C. Two assemblies shown in (A) and (B) stacked on top of each other, constitute the pump array that controls the suction. Notice the y connectors and mp-cv valves. D. The 26-pin Assembled Pi Cobbler Breakout Board is connected to 26-pin shield stacking headers with longer pins, so as to allow enough clearance for two of the mp6-OEM controllers that are attached directly adjacent to it. E. Cable that connects six micropumps to the Pi Cobbler Breakout Board. F. Mini-Faraday cages made of copper wire mesh to allow grounding the noise from the pumps.

Note: Alpha Wire multiconductor cables have their own color scheme which is unrelated to the color scheme of Figures 2B, 2C, 9 and 11.

\section{Part II: Rodent Hippocampal Slice Preparation}

1. Prepare Dissection and Recording Solutions: Prepare two stock 10x ACSF solutions, one for dissection (Dissection 10x ACSF) and one for recording (Recording 10x ACSF). Maintain the two stock 10x ACSF solutions at $4^{\circ} \mathrm{C}$ until the day of the experiment.

2. On the day of the experiment, prepare $1 \times$ Dissection ACSF and 1x Recording ACSF.

3. Oxygenate both solutions for at least $20 \mathrm{~min}$ at room temperature with $95 \% \mathrm{O}_{2} / 5 \% \mathrm{CO}_{2}$.

4. Reducing the temperature of the slice helps prevent ischemic damage (see Note 2). To rapidly 
chill room-temperature 1x Dissection ACSF Buffer to an appropriate cold temperature without freezing the buffer, place it into a $-70{ }^{\circ} \mathrm{C}$ freezer for $45 \mathrm{~min}$. If ice crystals form, remove them with a small spoon or sieve to avoid contact with, and possible damage to the brain tissue. After removing from the freezer continue to oxygenate the Dissection ACSF with $95 \% \mathrm{O}_{2} / 5 \% \mathrm{CO}_{2}$ at $4{ }^{\circ} \mathrm{C}$.

5. Prepare the interface electrophysiology rig: Heat the water jacket of the interface chamber so that the temperature of the recording chamber is $31.5{ }^{\circ} \mathrm{C}$. Preheat $250-500 \mathrm{ml}$ of the $1 \mathrm{x}$ Recording ACSF by placing it in a $32{ }^{\circ} \mathrm{C}$ water bath while oxygenating with $95 \% \mathrm{O}_{2} / 5 \% \mathrm{CO}_{2}$. The purpose of preheating the solution to a temperature slightly above the temperature of the recording chamber is to prevent the formation of bubbles in the tubes and under the mesh when the solution is heated again after passing from the heat jacket. Start perfusing the bath with 1x Recording ACSF, at a flow rate of $500 \mu \mathrm{l} / \mathrm{min}$.

6. Deeply anesthetize the animal in the anesthesia chamber, using an Isoflurane vaporizer: Apply $100 \% \mathrm{O}_{2}$ for $2 \mathrm{~min}$, followed by $100 \% \mathrm{O}_{2}+1.5 \%$ Isoflurane for $1 \mathrm{~min}$, followed by $100 \% \mathrm{O}_{2}+$ $2.5 \%$ Isoflurane for $2 \mathrm{~min}$.

7. When the animal is deeply anesthetized, decapitate it with a small animal guillotine. Submerge the decapitated head inside a metal surgical tray sitting on ice in an icebox and filled with oxygenated ice-cold 1x Dissection ACSF.

Note: Following the decapitation of the animal, the preparation of the brain slices should be completed within less than 10 min.

8. Quickly remove the brain: expose the skull by making an incision with a single edge razor blade on the scalp.

9. Using a pair of surgical scissors with their sharp pointed blade working along the inner side of the skull, cut along the sagittal suture from the foramen magnum to the forehead.

10. Using the surgical scissors, make one cut at the foramen magnum on each temporal side of the skull, then cut across the frontal bone along the coronal suture. Carefully pry the skull open with a rongeur and expose the brain.

11. Holding the skull upside down, sever the cranial nerves that hold the brain to the skull using a spatula and allow the brain to fall into a $50 \mathrm{ml}$ beaker containing ice-cold oxygenated $1 \mathrm{x}$ Dissection ACSF.

12. Using an icebox, transfer the beaker with the brain to a $4{ }^{\circ} \mathrm{C}$ cold room.

13. Isolate the hippocampus: use a $90 \mathrm{~mm}$ Pyrex Culture Petri Dish covered with a moistened filter paper as a dissecting platform.

14. Place the chilled brain on the platform and bisect it along the longitudinal fissure. Place the right hemibrain in a $50 \mathrm{ml}$ beaker containing ice-cold oxygenated 1x Dissection ACSF.

15. To isolate the hippocampus of the left hemibrain, sever what remains of the midbrain and brain-stem using a flat spatula. Scoop out the thalamus to expose the ventral face of the hippocampus nested inside the cortex and clearly visible as a curved structure. Sever the septal and temporal connections of the hippocampus from the cortex with a spatula. Using a 
filled plastic Pasteur pipet, gently squeeze a few droplets of ice-cold oxygenated 1x Dissection ACSF into the pocket of the lateral ventricle to distinguish the border of the fimbria.

16. Gently insert into the lateral ventricle a fine brush moistened with ice-cold oxygenated $1 \mathrm{x}$ Dissection ACSF and roll the hippocampus out gently from the surrounding cortex. Isolate the peeled-out hippocampus by cutting it free from the cortex using a flat spatula. Place the left hippocampus in a $20 \mathrm{ml}$ beaker with ice-cold oxygenated 1x Dissection ACSF.

17. Repeat previous steps with right hippocampus.

18. Slicing: The slicing stage should be prepared in advance and can be reused multiple times. It consists of a circular thin piece of cork pad of equal diameter to the plastic disc of the Mcllwain tissue chopper and glued on it with parallel pieces of double-sided adhesive tape. The clamps of the Mcllwain tissue chopper dissection platform can be adjusted to match the thickness of the slicing stage (Figure 16C).

19. Place a piece of filter paper on the slicing stage and moisten it with chilled oxygenated $1 x$ Dissection ACSF.

20. Using a fine brush (or a spatula with its flat side bent at right angles) gently lift the hippocampus from the bottom of the beaker.

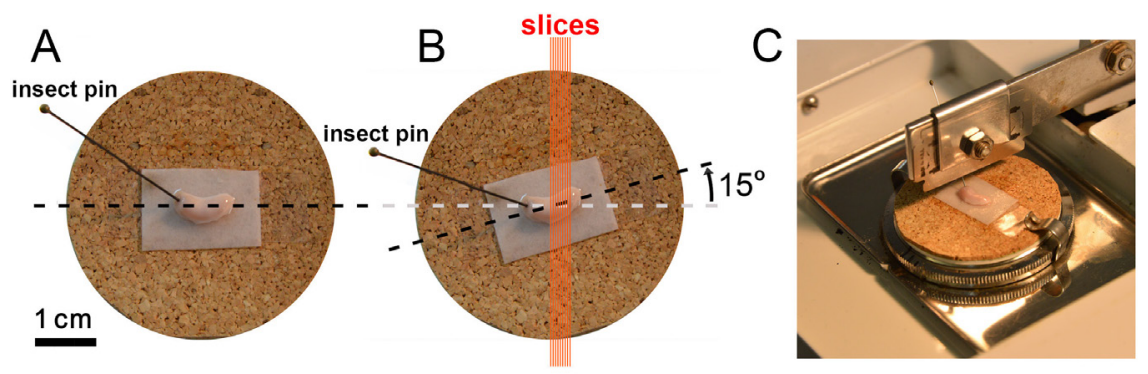

Figure 16. Photographs showing proper positioning of the left rat hippocampus on the Mcllwain tissue chopper dissection platform (refer to text for details)

21. Lay the isolated hippocampus on the slicing stage with its top side up (the dorsal face containing the alveus). It is often possible to view striations on the alvear surface of this side, with oblique light from a fiber optic. Using the brush gently straighten the bottom surface of the hippocampus so that it lies completely flush on the moistened filter paper.

22. Only the dorsal hippocampus will be sliced from each side. To immobilize the hippocampus, one may therefore affix the ventral hippocampus (the thicker end) on the cork of the slicing stage with an insect pin (Figure 16A).

23. Slide the slicing stage with the affixed hippocampus through the clamps of the Mcllwain tissue chopper dissection platform (Figure 16C).

24. Rotate the slicing stage on the platform so that the dorsal hippocampus is properly oriented with respect to the razor blade: the blade should make a $15^{\circ}$ angle with the transverse axis of the dorsal hippocampus (Figures 16B, 16C). Excitatory pathways are better preserved when an angle of 15 to $30^{\circ}$ from this axis is used (Alger et al., 1984). In general, the alvear striations 
will tend to run parallel to the blade at this orientation. If the hippocampus on the left hemibrain is used, it will look like an upright " $U$ " as viewed from above with the dorsal hippocampus on the right and the (pinned) ventral hippocampus on the left (Figures 16A-16C). To achieve the proper cutting angle, rotate the slicing stage $15^{\circ}$ counterclockwise. Similarly, if the right hippocampus is used, it will resemble an inverted "U", and the stage is rotated $15^{\circ}$ clockwise.

25. Wet the blade with ACSF and make the slices by lowering the blade through the hippocampus. Each slice should stick on the wet surface of the blade as it ascends. The first 3 (most dorsal) complete slices are usually discarded. Depending on the age of the animal, 6 to 8 slices of 450 $\mathrm{mm}$ thickness can be obtained from rats (Figure 16B) and 4-5 such slices from mice. The speed and the strength of impact of the blade should be adjusted so that the slices are cut gently, but quickly enough to avoid sticking of the uncut hippocampus on the ascending blade. The blade should not slam on the surface of the cutting stage; ideally it should just dimple the surface of the wet filter paper on the chopping stage.

26. Quickly remove the slices from the blade as they are produced using a moistened fine sable brush. Immediately after making each slice, transfer it to a test tube filled with ice-cold oxygenated $1 \mathrm{x}$ Dissection ACSF. Take great care to avoid stretching or excessively bending the slices during handling. One method is to pick the slices from the blade with the brush premoistened with ice-cold oxygenated 1x Dissection ACSF, using a gentle rolling motion. Some of the ACSF moisture on the brush will also stick on the blade and help the next slice stick to the blade after it has been sliced off the hippocampus.

27. Immediately after making the slices, transfer them to the interface recording chamber to recover for at least $2 \mathrm{~h}$. The slices should rest on a mesh at the gas-liquid interface, forming a small meniscus around them (Figures 17A, 17B and 17C), and should be constantly superfused from both their top and bottom side with (non-recirculating) 1x Recording ACSF, at a flow rate of $500 \mu \mathrm{l} / \mathrm{min}$.

Note: Please also consult the following video articles offering detailed information on acute hippocampal slice preparation for long-term recordings: Villers and Ris (2013); Shetty et al. (2015).


Figure 17. Photographs showing proper positioning of a rat hippocampal slice in an Oslo-type interface recording chamber. A. The slice lies on a mesh, near the wall of a recording bath. The chamber has two such recording baths, both of which are covered by a removable convex canopy that creates a humidified, oxygen-rich atmosphere above the slice. 
The canopy has a triangular opening that allows recording from each slice individually (while the slice in the other bath remains covered). Each slice is constantly superfused with ACSF flowing into the bath through an inflow tube and out through an outflow conduit (across from the inflow), which leads to the suction well (the suction is provided by a yellow syringe needle). B and $\mathrm{C}$. At interface, a small meniscus is formed around the slice. A larger meniscus is formed around the walls of the bath.

\section{Part III: Application of oligodeoxynucleotides to slices in recirculation mode}

In ODN experiments, after recovery from dissection in interface mode, increase the bath level to fully submerge the slices and allow the superfusate containing $20 \mu \mathrm{M}$ of the oligodeoxynucleotide to recirculate $(5 \mathrm{ml}$ total volume at $5 \mathrm{ml} / \mathrm{min}$ for $30 \mathrm{~min}$ ). To achieve this, follow these steps:

1. Copy and load the program of Figure 18 on the top Arduino of Figure 14 ("Microcontroller 1" in Figure 2A). Change the value of "delay" to "1800000", save the new program and reload to top Arduino. Upon activation by the digital output of ADC via the winLTP program, the top Arduino will turn on all six of the micropumps for $30 \mathrm{~min}$.

2. Load the Arduino PWM library (see link) and copy and load the program of Figure 19 on the bottom Arduino of Figure 14 ("Microcontroller 2" in Figure 2). Change the "int32_t clockfrequency" value to "200", save the new program and reload to the bottom Arduino. Upon activation by the digital output of the ADC via the winLTP program, the bottom two pumps will supply a flow rate of 5 $\mathrm{mL} / \mathrm{min}$ (Figure 20) to the inlets of the recording chamber (the four ouflow pumps of the suction, once on, will always operate at maximum flow rate).

3. Turn off the peristaltic pump, and at the same time turn off the vacuum suction.

4. Turn on the piezoelectric pump circuit using the SPST push button master switch.

5. Use a three-way valve to manually switch between the peristaltic pump drawing solution from a main reservoir (typically a $250 \mathrm{ml}$ Erlenmeyer flask held inside a water bath with a clamp) and the two-micropump assembly of the bath inlet, which should be drawing solution from a $15 \mathrm{ml}$ conical tube containing the recirculating solution with the ODN (inside the same water bath as the main reservoir).

6. Start the winLTP program with Sequential Protocol Scripting and Automated Perfusion Control (Anderson et al., 2012; see also Chapter 10 of the WinLTP software manual (Anderson, 2018).

Note: The automated perfusion control is currently only supported by National Instruments $M$ - or $X$-Series ADC boards). Use the Slow0 Perfusion Change for controlling one perfusion line to one extracellular slice chamber. 


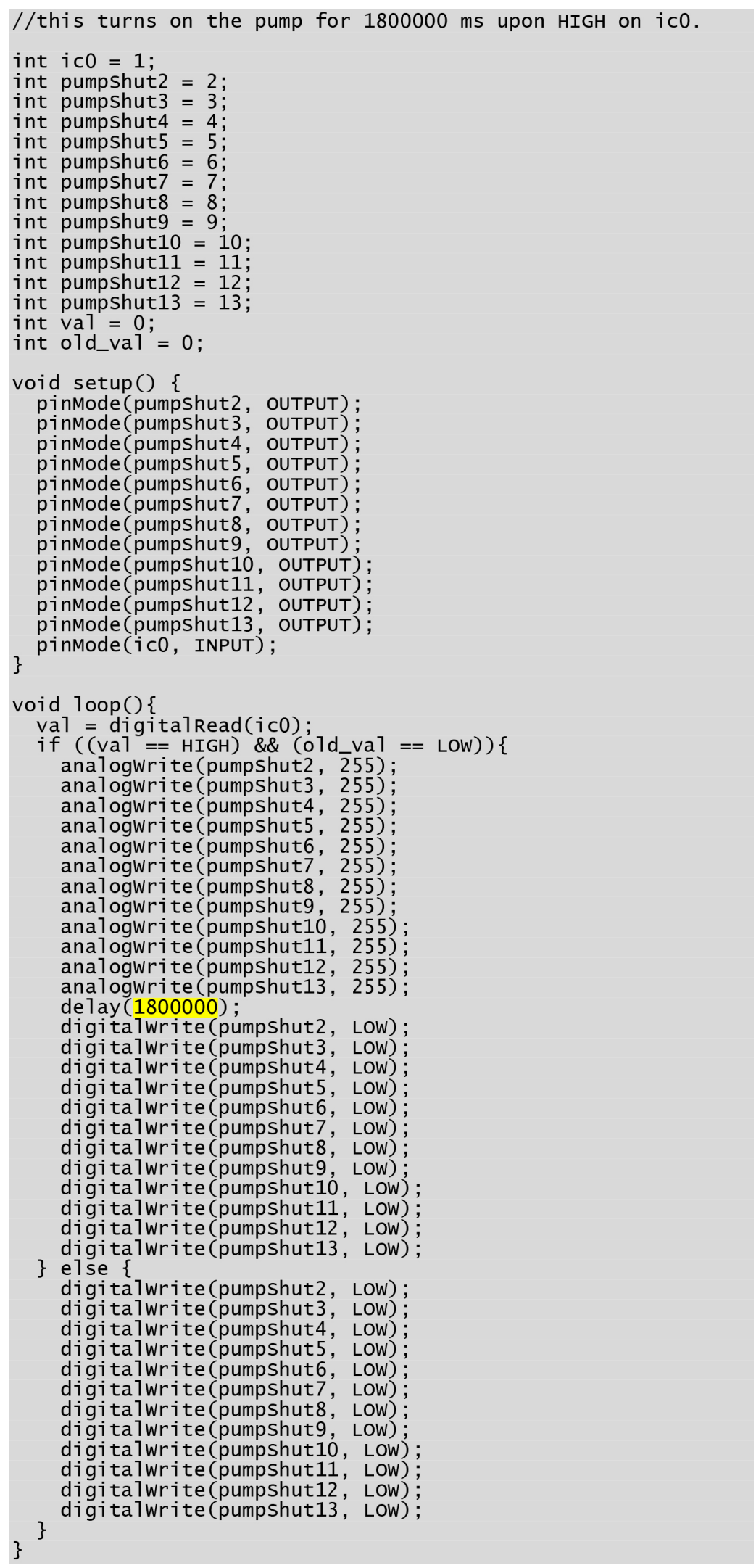

Figure 18. Arduino program that activates simultaneously all six mp6 oems and keeps them active for a designated period. The program allows turning all six of the mp6 micropumps on simultaneously when prompted by one of the digital outputs of the ADC, which 
is in turn controlled by the "Slow0 Perfusion Change" function of the winLTP program. By changing the "delay" value (highlighted in yellow) the slices can be perfused for variable intervals. In this particular example the pumps will remain on for $1800000 \mathrm{~ms}$ (i.e., $30 \mathrm{~min}$ ).

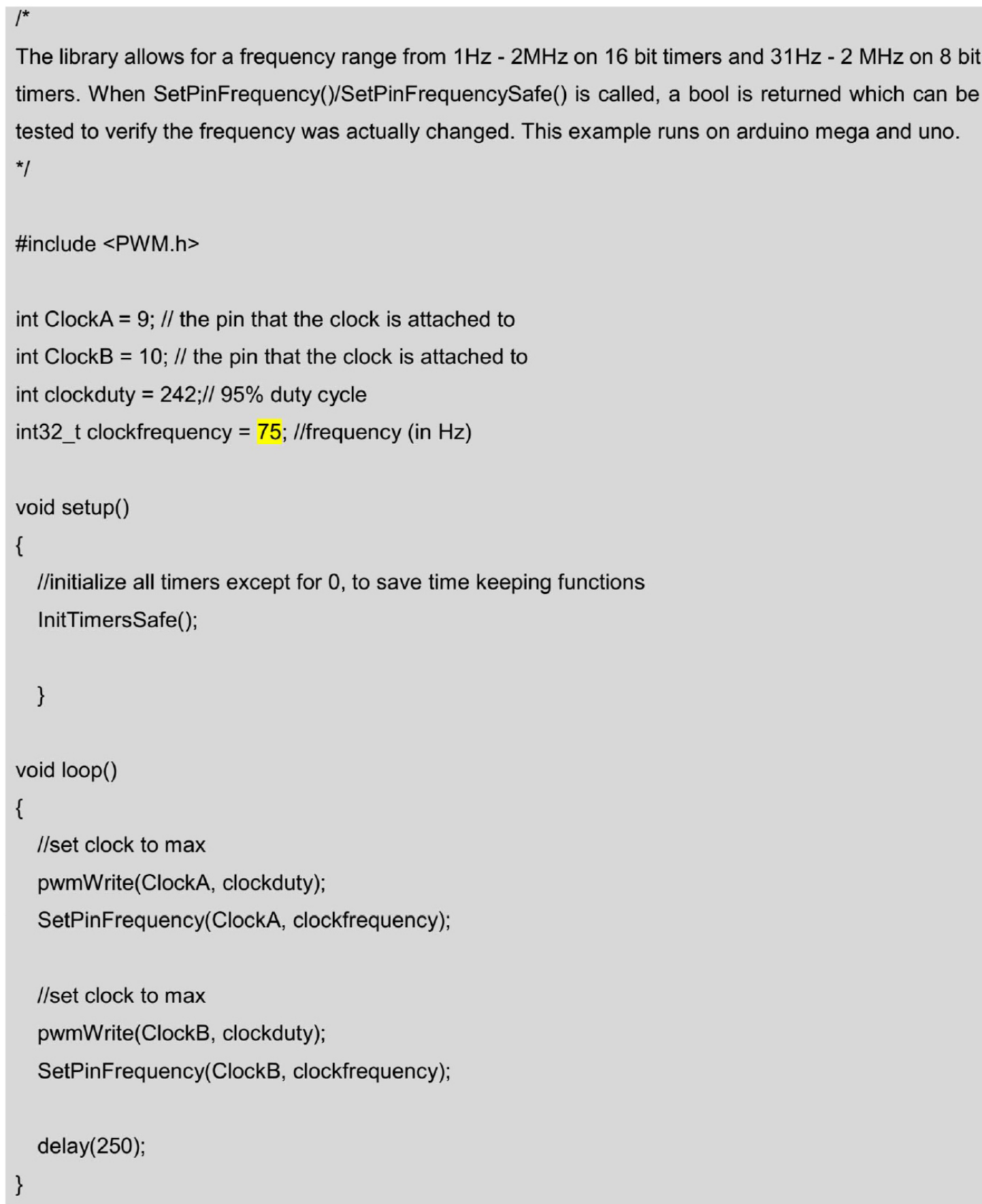

Figure 19. Arduino program that performs pulse width modulation (PWM). The program allows changing the frequency of the signal generated by the mp6-OEM from the default value, to reduce the mp6 micropump flow volume from its maximum value $(5.5 \mathrm{ml} / \mathrm{min})$. The frequency of the OEM signal is altered by changing the value of "int32_t clockfrequency" 
(highlighted in yellow). The current value "int32_t clockfrequency $=75$ " yields a flow rate of approximately $2.5 \mathrm{ml} / \mathrm{min}$ (see Figure 20 ).

Note: Library download link:

https://code.google.com/archive/p/arduino-pwm-frequency-library/downloads.

Note: The digital output from the National Instruments $M$ - or $X$-Series board is connected to Arduino 1, and it will activate both the assembly consisting of the two independent micropumps that control the inlets to the bath, as well as the multipump array that controls the suction. Make sure the tube at the output of the aspirator leads the solution back to the $15 \mathrm{ml}$ conical tube to complete the recirculation circuit.

7. If necessary, adjust the height of the suction tube in the suction well of the chamber to raise the bath level and fully submerge the slice.

8. After $30 \mathrm{~min}$ of recirculation in the submersion mode and to begin recording, lower the bath level of the ODN-containing solution by lowering the aspirator tube to interface level and return the flow rate to $0.5 \mathrm{ml} / \mathrm{min}$ for the remainder of the experiment by changing the "int32_t clockfrequency" value from 200 to 10, and loading again the program of Figure 19 to the Bottom Arduino Uno.

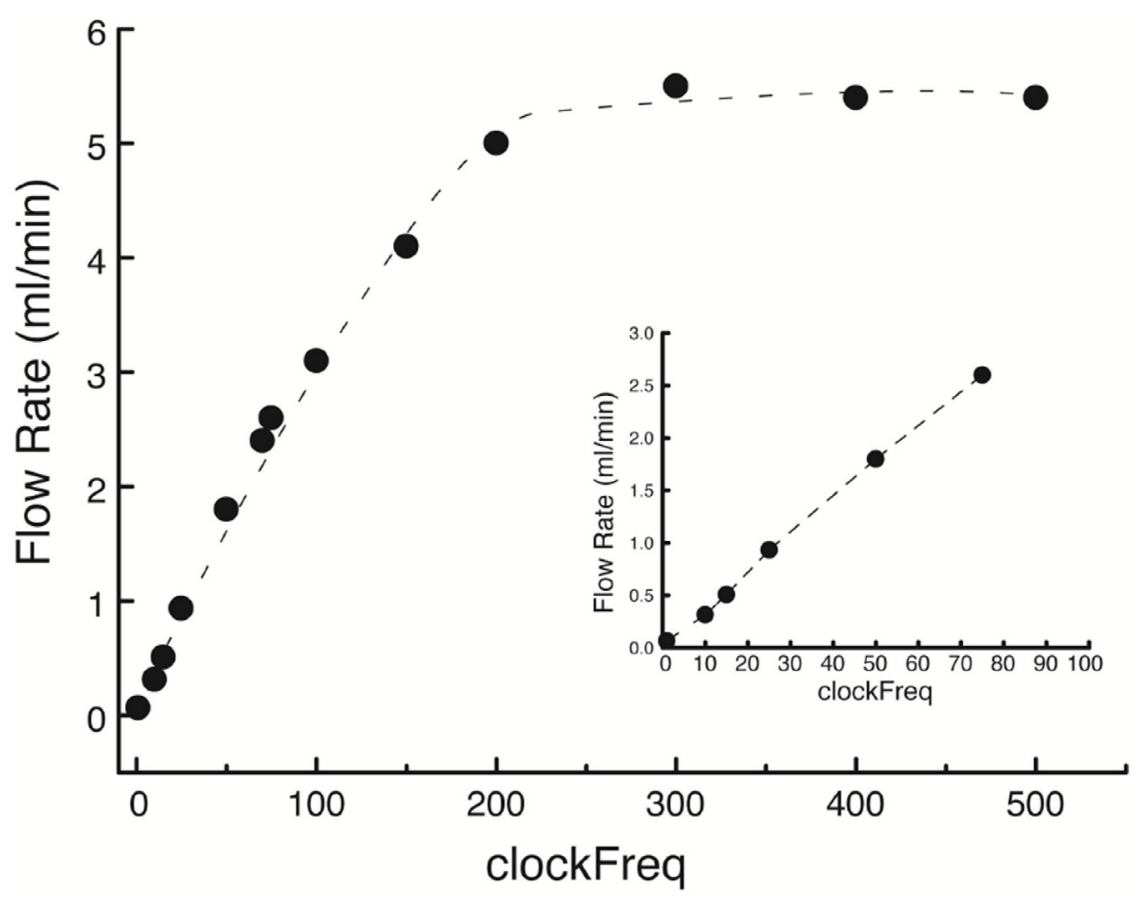

Figure 20. Changing the flow rate of single mp6 micropump by pulse-width modulation (PWM). By inserting different values for "int32_t clockfrequency" (x-axis of the graph), the flow rate ( $y$-axis) can be changed from the low rates of a few hundred microliters per min (shown in the insert) required for interface chamber recordings, to a maximal flow rate of $5.5 \mathrm{ml} / \mathrm{min}$. 
9. Place stimulating and recording electrodes in the hippocampal layers of interest and begin electrophysiological recordings.

10. For experiments to study long-term synaptic plasticity lasting many hours, record field EPSPs (fEPSPs) with a glass extracellular recording electrode (2-5 M 2 ) placed in the CA1 stratum radiatum, with concentric bipolar stimulating electrodes placed on either side within CA3 or CA1. Exclude from study slices if initial analysis shows fEPSP spike threshold $<2 \mathrm{mV}$. Confirm independence between the two stimulated pathways by the absence of paired-pulse facilitation between the two pathways. Set the baseline fEPSP at $25 \%$ of the spike threshold and monitor it by delivering stimuli at $0.033 \mathrm{~Hz}$ to each pathway. Induce LTP by strong HFS, consisting, for example, of standard two $100 \mathrm{~Hz}-1 \mathrm{~s}$ tetanic trains, spaced $20 \mathrm{~s}$ apart, which is optimized to produce a relatively rapid onset of protein synthesis-dependent late-LTP (Tsokas et al., 2005; Tsokas et al., 2016, Hsieh et al., 2017). For rat hippocampal slices deliver the tetanus at $70 \%$ of the spike threshold (Tsokas et al., 2005; Hsieh et al., 2017), and for mouse slices use $25 \%$ of the spike threshold (Tsokas et al., 2016). The maximum slope of the rise of the fEPSP can be analyzed on a PC using the WinLTP data acquisition program (Anderson and Collingridge, 2007).

\section{Notes}

1. Comparison of interface and submersion chamber: oxygenation and efficacy of aPKC inhibitor ZIP on synaptic transmission

Most studies examining long-term synaptic plasticity in hippocampal slices, employ Oslo-type interface recording chambers, rather than submerged chambers, because the former are believed to provide superior oxygenation and preservation of normal synaptic function (Khurana and $\mathrm{Li}, 2013$ ). We tested this assumption, by using a galvanic dissolved-oxygen probe (Atlas Scientific KIT-106; zinc anode, silver cathode, 15\% sodium tetraborate/15\% sodium chloride electrolyte; polyethylene membrane) to measure the dissolved oxygen (DO) concentration in the Oslo-type interface recording chamber and in the same chamber used in submersion mode with flow rates ranging from 2 to $15 \mathrm{ml} / \mathrm{min}$.

The dissolved oxygen probe was calibrated using distilled water and ambient air, as described by the manufacturer. The accuracy of the instrument was further tested by measuring dissolved atmospheric oxygen in ACSF $(14,000 \mu \mathrm{S} / \mathrm{cm})$ at room temperature $\left(23.5{ }^{\circ} \mathrm{C}\right)$. The average value $(8.1 \pm 0.01 \mathrm{mg} / \mathrm{L} ; \mathrm{n}=5)$ was in agreement with previously reported data for atmospheric dissolved oxygen equilibrium at different temperatures and salinity conditions (Radtke et al., 1998).

Air from a medical air cylinder, or $100 \%$ oxygen (both from TW Smith) was then bubbled through the gas dispersion ring (or the ceramic aerators) of the water jacket of the Oslo-type chamber at $31.5{ }^{\circ} \mathrm{C}$, and the concentration of dissolved oxygen was measured inside the recording chamber, under interface conditions, with the probe clamped on a micromanipulator 
and held a few millimeters above the surface of the mesh (where the meniscus surrounding the slice is normally formed). A standard curve of oxygen saturation vs. concentration was thus generated for the tip of the probe moistened with ACSF $\left(6.9 \pm 0.3 \mathrm{mg} / \mathrm{L}\right.$ at $21 \% \mathrm{O}_{2} ; 31.1 \pm 0.8$ $\mathrm{mg} / \mathrm{L}$ at $100 \% \mathrm{O}_{2} ; \mathrm{n}=5$; linear fit through $0, \mathrm{r}^{2}=0.99$ ). With $95 \% \mathrm{O}_{2}-5 \% \mathrm{CO}_{2}$ bubbling through the water jacket, the oxygen concentration immediately above the slice at the interface was $29.6 \pm 0.7 \mathrm{mg} / \mathrm{L}(95.1 \pm 2.3 \%$ saturation; $\mathrm{n}=5)$.

The Oslo-type chamber was then converted into a submersion chamber: the suction was raised to increase the level of the superfusate inside the recording bath, the oxygenation via the aerators in the water jacket was turned off, and the flow rate was increased to obtain oxygen concentration/saturation measurements at 2, 5, 10 and $15 \mathrm{ml} / \mathrm{min}$. Under submersion conditions, and immediately above the position where the slice would be in an actual experiment, the following oxygen concentration $(\mathrm{mg} / \mathrm{L})$ and $\%$ saturation measurements were obtained (n's = 4) $-2 \mathrm{ml} / \mathrm{min}: 19.6 \pm 0.9(62.5 \pm 2.8 \%) ; 5 \mathrm{ml} / \mathrm{min}: 22.7 \pm 1.4(72.4 \pm 4.6 \%) ; 10$ $\mathrm{ml} / \mathrm{min}: 25.5 \pm 1.7(81.6 \pm 5.7 \%)$; and $15 \mathrm{ml} / \mathrm{min}: 26.9 \pm 1.9(86.3 \pm 6.2 \%)$. These measurements are in agreement with values reported for different types of submersion chambers described elsewhere, using carbon-fiber microelectrodes, DO optical sensors, polarographic cells (i.e., amperometric Clark electrodes), or a colorimetric chemical (indigo carmine) methods (Hájos et al., 2009; Dondzillo et al., 2015; Weng et al., 2018).

These results demonstrate that the oxygen saturation in the superfusate of submersion chambers (see, for example, Volk et al., 2013) is substantially lower than in the humidified atmosphere that envelops slices in Oslo-type interface chambers, especially at the flow rates commonly used $(72.4 \pm 4.6 \%$ for a submersion chamber with flow rate $5 \mathrm{ml} / \mathrm{min}$, compared to $95.1 \pm 2.3 \%$ for an Oslo-type interface chamber). The effects of lower oxygen saturation on slice health might be further exacerbated when the slices are recovered under submerged conditions after preparation (as in Volk et al., 2013).

We next asked whether the differences of oxygenation obtained in interface vs. submerged chambers have physiological effects on synaptic physiology. We specifically addressed whether chamber design might explain a difference that has been reported in the effects of the atypical PKC inhibitor ZIP on basal synaptic transmission. Whereas consistently ZIP reverses late-LTP in all published studies in which it has been studied (see, for example Ling et al., 2002; Sajikumar et al., 2005; Pastalkova et al., 2006), in most of these studies the effect of the PKM inhibitor is specific to potentiated synaptic pathways with no effect on basal, untetanized synaptic pathways. This specificity of the inhibitor to potentiated and not basal synaptic transmission is identical to results obtained with applications of the agent to LTP and basal synaptic transmission recorded in vivo (Pastalkova et al., 2006; Madroñal et al., 2010). However, one study reported that ZIP had effects on both late-LTP and baseline synaptic transmission (Volk et al., 2013). This study, however, was unusual in that the late-LTP recordings and basal synaptic transmission were recorded in hippocampal slices held in a submerged chamber. 
We therefore directly compared the effects of ZIP on LTP and baseline synaptic transmission in hippocampal slices recorded in an interface and in a submersion chamber. To keep all other parameters as constant as possible, the interface chamber slices recovered in the same chamber in which their recordings take place; whereas the submersion chamber slices were placed in an interface chamber, which was then immediately converted into a submersion chamber by increasing the flow rate and bath level of the ACSF solution, and the slices were then allowed to recover for another $90 \mathrm{~min}$ (the total recovery time of both sets of slices in the two experiments is kept equal).

As seen in Figure 21, in slices recovered and recorded in an interface chamber, ZIP specifically reverses late-LTP maintenance in the tetanized pathway without affecting basal neurotransmission in the untetanized pathway. In contrast, in slices recorded under submerged conditions, ZIP reverses LTP maintenance, eventually below baseline, and also has an effect on an independent untetanized pathway. This effect of ZIP on the untetanized/basal pathway was similar to that seen in Volk et al. (2013).

A plausible explanation for this difference is that there is a pool of atypical PKC involved in neuroprotection from hypoxia (see Tian et al., 2008) that is separate from the pool of PKM $\zeta$ that maintains late-LTP. Because the oxygenation conditions in an interface chamber are superior to those for submerged slices, the effect of ZIP on basal neurotransmission in a submersion chamber may reflect the effects of the inhibitor on the neuroprotective role of atypical PKC that is induced by the relatively hypoxic conditions of the slice (Tian et al., 2008). Alternatively, the low-oxygen conditions of submerged chambers may have induced hypoxic LTP in the untetanized synapses, rendering them sensitive to ZIP. Importantly, as mentioned above, the specificity of ZIP to potentiated and not basal synaptic transmission is seen in vivo in the hippocampal perforant path dentate gyrus input (Pastalkova et al., 2006), hippocampal CA3-CA1 (Madroñal et al., 2010), and layer 4 primary visual cortex (Cooke and Bear, 2010). Thus, high-oxygen interface chambers, but not low-oxygen submerged chambers appear to produce conditions of synaptic transmission and plasticity that more closely reflect in vivo conditions.

In addition to inferior oxygenation conditions, another factor that may have contributed to the artifactual response to ZIP of the untetanized pathway in Volk et al. (2013) is the intensity of the conditioning stimulus used to induce late-LTP. The intensity of the Volk et al. (2013) protocol, which was delivered at $75 \%$ of the maximum EPSP response, is appropriate for rat Schaffer collateral/commissural-CA1 synaptic stimulation, but is much higher than what is normally used to induce LTP in mouse hippocampal slices, which is typically between $25 \%$ of the spike threshold, as in Tsokas et al. (2016), and 50\% of maximum EPSP in Abel et al. (1997), Nguyen et al. (2000), Barco et al. (2002), Opazo et al. (2003), Selcher et al. (2003), Kelleher et al. (2004), Costa-Mattioli et al. (2005), Antion et al. (2008), Pavlowsky and Alarcon (2012), Gruart et al. (2012), Li et al. (2017), Puzzo et al. (2017), Amorim et al. (2018). Such strong repetitive synaptic stimulation in Volk et al. (2013) may have further undermined neuronal health, thereby 
contributing to the artifactual drop below the baseline of the EPSP in the untetanized pathway in response to ZIP.
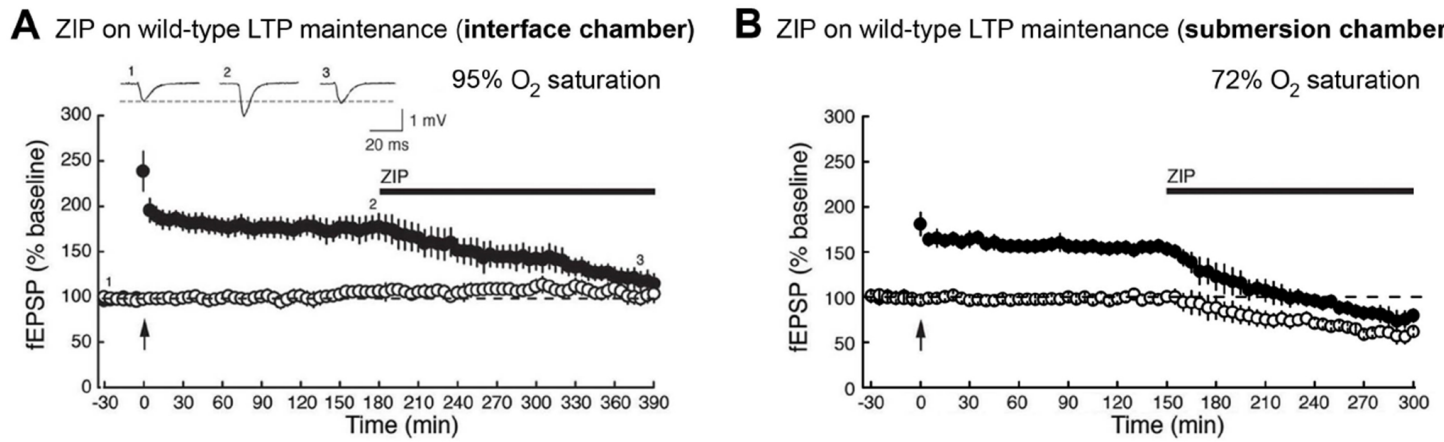

Figure 21. Brain slice late-LTP experiments in an interface vs. submersion chamber. A. ZIP $(5 \mu \mathrm{M})$ applied during the maintenance phase of late-LTP reverses potentiation without effect on the untetanized pathway (from Tsokas et al., 2016; $n=5)$. B. In contrast, in slices $(n=$ 3 ) that have recovered in an interface chamber (for equal time as the slices in $A$ ), which was then converted into a submersion chamber by increasing the bath level and flow rate of the ACSF, $5 \mu \mathrm{M}$ ZIP not only reverses LTP in the tetanized pathway but also decreases basal synaptic transmission in the untetanized pathway. This difference may be due to the superior oxygenation conditions in interface chambers (oxygen saturation is $95.1 \pm 2.3 \%$ in an Oslo-type interface chamber, compared to $72.4 \pm 4.6 \%$ in a submersion chamber with a typical flow rate of $5 \mathrm{ml} / \mathrm{min}$ ).

\section{Protection from excitotoxicity}

In order to protect from excitotoxicity during the slice-making process we recommend using ice-cold high magnesium/low calcium ACSF solutions and performing the slice preparation procedure inside a $4{ }^{\circ} \mathrm{C}$ cold room.

Lowering the temperature decreases the metabolic rate of cells thus reducing their energy consumption, allowing the cells to survive ischemia during slice preparation. In addition, we recommend using a special, non-physiological ACSF during dissection (Dissection ACSF) that contains $10 \mathrm{mM}$ magnesium and $0.5 \mathrm{mM}$ calcium. Both these departures from physiological CSF are known to reduce excitotoxicity (Feig and Lipton, 1990; Sacktor et al., 1993; Wang and Kass, 1997; Ting et al., 2018).

3. mp6 micropump noise

There are two sources of noise in the system: (a) noise from the electrical signal of the OEM, and (b) noise generated in the solution because of the vibration of the ionic ACSF by the pump actuators. These sources of noise can be completely silenced by (a) making a metal enclosure for the circuit and mini-Faraday cages for the pump "sandwich" arrays, and (b) grounding the recirculating ACSF both at the inflow to the bath and at the suction, using T-shape tubing connectors with a silver chloride wire connected to the main ground of the rig. 
4. Passive check valves mp-cv

To eliminate potential back flow of the ACSF owing to differential pressure between the pump inlet and the outlet (due to differences, for example, between the height of the recording chamber and the height of the ACSF reservoir, or the connecting tubes), use a passive check valve encased in stainless steel manufactured by Bartels Mikrotechnik (mp-cv). The valve, which will influence the volume flow of the micropump, should be placed between the micropump and the outflow reservoir. Figure $15 \mathrm{C}$ shows four such mp-cv check valves connected to the array of four mp6 micropumps controlling the suction of the interface recording chamber.

5. Metal enclosure for the piezoelectric pump system

For safety reasons (to protect against electric shock from the OEMs), as well as to eliminate the noise produced by the OEMs and to protect the circuit from damage, the completed circuit of Figure 14 should be placed inside a metal enclosure that is grounded. The enclosure should have an opening for the ribbon cable of the Breakout Board connecting the micropump assemblies, as well as openings for the power supply cables, the two USB cables of the Arduinos, the master switch of the circuit, and the BNC cable connecting the top Arduino to the ADC board.

6. Hybrid persistaltic/piezoelectric pump arrangement

A simplified alternative to the recirculation device described here is to use piezoelectric pumps only for the aspirating the recirculation ACSF, and a peristaltic pump to provide the inflow to the chamber. In this arrangement, a peristaltic pump with a two-channel pump head would control the inflow (alternatively, a four-channel pump head can be used, if the interface chamber supports two independent baths for slices). One piezoelectric array (or two, depending on the number of baths supported by the interface chamber) would control the aspirator, with each array consisting of four mp6 micropumps driven by the suction part of the circuit (i.e., the top four OEMs) at the maximum flow rate.

7. Pre-flushing the dead volume of the perfusion system before switching solutions

When $95 \% \mathrm{O}_{2}-5 \% \mathrm{CO}_{2}$-aerated ACSF stays in polyethylene or Tygon tubing for a long time before being perfused onto slices, it degases and becomes hypoxic. The loss of carbon dioxide also alters the $\mathrm{pH}$ of the standard bicarbonate buffer of the ACSF. It is therefore important to "pre-flush" the dead volume in the perfusion system before switching solutions.

In the experiments described in Tsokas et al. (2016), two manual three-way valves in series allowed pre-flushing the dead volume in the tubing of the inflow mp 6 micropump assemblies by switching the upstream three-way valve from the idle peristaltic pump (OFF) to the idle mp6 micropump (ON), and switching the downstream three-way valve so that the outflow from the micropump flows directly into waste (ON), rather than into the slice chamber (OFF). In this configuration, turning the micropump on for 10 seconds before switching it back off allows the dead volume to clear. Following this procedure, first turn the downstream valve's outlet to the waste to OFF, before turning the mp6 micropump back on to resume operation of the perfusion 
system.

WinLTP 2.30 has four perfusion line controls (Slow0, Slow1, Fast0, and Fast1) that can be used for controlling piezo steppers and pinch valves for automatic changing of bath perfusion. For an excellent discussion of how to use these features with commercially available pinch valve systems for automated pre-flush perfusion of slices, see Chapter 10 of the WinLTP 2.30 manual (Anderson, 2018).

8. The mp6 micropumps are sensitive and will be severely damaged if liquid is forced into them by applying pressure with a syringe. If the micropumps fail to draw liquid when initially turned on (usually due to incomplete purging of their contents during previous use), it is best to connect the inlet of the $\mathrm{mp} 6$ to proper tubing attached to the tip of a vertically positioned $20 \mathrm{ml}$ syringe barrel (i.e., without the plunger, and with its tip pointed towards the ground). Turn the micropump on, pour a few $\mathrm{mL}$ of water into the barrel of the syringe, and allow gravity to assist the micropump's vibrating piezoelectric diaphragms in clearing the chambers of the pump.

\section{Recipes}

1. 10x Stock Dissection ACSF Buffer (store at $\left.4{ }^{\circ} \mathrm{C}\right)($ Table 1)

Table 1. Recipe for preparing 10x Stock Dissection ACSF Buffer (store at $4{ }^{\circ} \mathrm{C}$ )

\begin{tabular}{lll}
\hline Reagent & Stock Concentration (10x) & For $1 \mathrm{~L}$ \\
\hline $\mathrm{NaCl}$ & $1.25 \mathrm{M}$ & $73.20 \mathrm{~g}$ \\
$\mathrm{KCl}$ & $25 \mathrm{mM}$ & $1.86 \mathrm{~g}$ \\
$\mathrm{NaH}_{2} \mathrm{PO}_{4}$ & $12.5 \mathrm{mM}$ & $1.50 \mathrm{~g}$ \\
$\mathrm{NaHCO}_{3}$ & $260 \mathrm{mM}$ & $21.84 \mathrm{~g}$ \\
\hline
\end{tabular}

2. $10 x$ Stock Recording ACSF Buffer (store at $4{ }^{\circ} \mathrm{C}$ ) (Table 2)

Table 2. Recipe for preparing 10x Stock Recording ACSF Buffer (store at $4{ }^{\circ} \mathrm{C}$ )

\begin{tabular}{lll}
\hline Reagent & Stock Concentration (10x) & For $1 \mathrm{~L}$ \\
\hline $\mathrm{NaCl}$ & $69.00 \mathrm{~g}$ \\
$\mathrm{KCl}$ & $1.18 \mathrm{M}$ & $2.61 \mathrm{~g}$ \\
$\mathrm{NaH}_{2} \mathrm{PO}_{4}$ & $35 \mathrm{mM}$ & $1.50 \mathrm{~g}$ \\
$\mathrm{NaHCO}_{3}$ & $12.5 \mathrm{mM}$ & $20.15 \mathrm{~g}$ \\
\hline
\end{tabular}


3. $1 x$ Dissection ACSF Buffer (prepare on the day of the experiment) (Table 3)

Table 3. Recipe for preparing 1x Dissection ACSF Buffer (prepare on the day of the experiment)

\begin{tabular}{lll}
\hline Reagent & Working Concentration (1x) & For 1 L \\
\hline $\mathrm{CaCl}_{2}$ & $0.5 \mathrm{mM}$ & $0.5 \mathrm{ml}$ of $1 \mathrm{M} \mathrm{CaCl}_{2}$ solution \\
$\mathrm{MgCl}_{2}$ & $10 \mathrm{mM}$ & $10 \mathrm{ml}$ of $1 \mathrm{M} \mathrm{MgCl}_{2}$ solution \\
$\mathrm{D}-(+)-$ Glucose & $11 \mathrm{mM}$ & $1.98 \mathrm{~g}$ \\
10x Dissection ACSF & & $100 \mathrm{ml}$ \\
Water & & $889.5 \mathrm{ml}$ \\
\hline
\end{tabular}

4. 1x Recording ACSF Buffer (prepare on the day of the experiment) (Table 4)

Table 4. Recipe for preparing 1x Recording ACSF Buffer (prepare on the day of the experiment)

\begin{tabular}{lll}
\hline Reagent & Working Concentration (1x) & For $1 \mathrm{~L}$ \\
\hline $\mathrm{CaCl}_{2}$ & $2.5 \mathrm{mM}$ & $2.5 \mathrm{ml}$ of $1 \mathrm{M} \mathrm{CaCl}_{2}$ solution \\
$\mathrm{MgCl}_{2}$ & $1.3 \mathrm{mM}$ & $1.3 \mathrm{ml}$ of $1 \mathrm{M} \mathrm{MgSO}_{4}$ solution \\
$\mathrm{D}-(+)$-Glucose & $15 \mathrm{mM}$ & $2.71 \mathrm{~g}$ \\
$10 \mathrm{x}$ Recording ACSF & & $100 \mathrm{ml}$ \\
Water & & $896.2 \mathrm{ml}$ \\
\hline
\end{tabular}

\section{Acknowledgments}

This piezoelectric micropump recirculation system and ODN delivery protocol was originally used in Tsokas et al. (2016). This work was supported by NIH grants R21NS091830 and R01MH099128 (AAF) and R37MH057068, R01MH115304, R01MH53576, R01DA034970, and the Lightfighter Trust (TCS). We thank Randy Andronica for technical assistance. The authors would like to thank Davide B. R. Bianchi (Boston University, Boston, MA) and Zoe B. Ravera (Ethical Culture Fieldston School, New York, NY) for building prototypes based on this protocol in order to test its accuracy. Panayiotis Tsokas is an Alexander S. Onassis Public Benefit Foundation Scholar.

\section{Competing interests}

The authors declare that no competing interests exist. 


\section{Ethics}

Animal experimentation: The experiment in Tsokas et al. (2016), were performed in strict accordance with the recommendations in the Guide for the Care and Use of Laboratory Animals of the National Institutes of Health. All of the animals were handled according to approved institutional animal care and use committee (IACUC) protocols (\#11-10274, \#12-10298, \#13-10363 of SUNY Downstate Medical Center or \#15-1459 of New York University). The protocols were approved by the Institutional Animal Care and Use Committee of SUNY Downstate Medical Center (Animal Welfare Assurance Number: A3260-01) and New York University (Animal Welfare Assurance Number: A3317-01). All surgery was performed under either ketamine and dexmedetomidine, isoflurane, or sodium pentobarbital anesthesia, and every effort was made to minimize suffering.

\section{References}

1. Abel, T., Nguyen, P. V., Barad, M., Deuel, T. A., Kandel, E. R. and Bourtchouladze, R. (1997). Genetic demonstration of a role for PKA in the late phase of LTP and in hippocampus-based long-term memory. Cell 88(5): 615-626.

2. Alger, B. E., Dhanjal S. S., Dingledine, R., Garthwaite, J., Henderson, G., King, G. L., Lipton, P., North, A., Schwartzkroin, P. A., Sears, T. A., Segal, M., Whittingham, T. S. and Williams, J. (1984). Brain Slice Methods. In: Brain Slices. Dingledine, R. (Ed.). Springer 381-442.

3. Amorim, I. S., Kedia, S., Kouloulia, S., Simbriger, K., Gantois, I., Jafarnejad, S. M., Li, Y., Kampaite, A., Pooters, T., Romano, N. and Gkogkas, C. G. (2018). Loss of elF4E phosphorylation engenders depression-like behaviors via selective mRNA translation. $J$ Neurosci 38(8): 2118-2133.

4. Anderson W. W. (2018). WinLTP Manual. Version 2.30. WinLTP Ltd. and School of Physiology and Pharmacology, University of Bristol.

5. Anderson, W. W. and Collingridge, G. L. (2007). Capabilities of the WinLTP data acquisition program extending beyond basic LTP experimental functions. $J$ Neurosci Methods 162(1-2): 346-356.

6. Anderson, W. W., Fitzjohn, S. M. and Collingridge, G. L. (2012). Automated multi-slice extracellular and patch-clamp experiments using the WinLTP data acquisition system with automated perfusion control. J Neurosci Methods 207(2): 148-160.

7. Antion, M. D., Merhav, M., Hoeffer, C. A., Reis, G., Kozma, S. C., Thomas, G., Schuman, E. M., Rosenblum, K. and Klann, E. (2008). Removal of S6K1 and S6K2 leads to divergent alterations in learning, memory, and synaptic plasticity. Learn Mem 15(1): 29-38.

8. Barco, A., Alarcon, J. M. and Kandel, E. R. (2002). Expression of constitutively active CREB protein facilitates the late phase of long-term potentiation by enhancing synaptic capture. Cell 108(5): 689-703. 
Please cite this article as: Tsokas et. al., (2019). Antisense Oligodeoxynucleotide Perfusion Blocks Gene Expression of Synaptic Plasticity-related

9. Cooke, S. F. and Bear, M. F. (2010). Visual experience induces long-term potentiation in the primary visual cortex. J Neurosci 30(48): 16304-16313.

10. Costa-Mattioli, M., Gobert, D., Harding, H., Herdy, B., Azzi, M., Bruno, M., Bidinosti, M., Ben Mamou, C., Marcinkiewicz, E., Yoshida, M., Imataka, H., Cuello, A. C., Seidah, N., Sossin, W., Lacaille, J. C., Ron, D., Nader, K. and Sonenberg, N. (2005). Translational control of hippocampal synaptic plasticity and memory by the elF2alpha kinase GCN2. Nature 436(7054): 1166-1173.

11. Dasgupta, A., Baby, N., Krishna, K., Hakim, M., Wong, Y. P., Behnisch, T., Soong, T. W. and Sajikumar, S. (2017). Substance $P$ induces plasticity and synaptic tagging/capture in rat hippocampal area CA2. Proc Natl Acad Sci U S A 114(41): E8741-E8749.

12. Dondzillo, A., Quinn, K. D., Cruickshank-Quinn, C. I., Reisdorph, N., Lei, T. C. and Klug, A. (2015). A recording chamber for small volume slice electrophysiology. J Neurophysiol 114(3): 2053-2064.

13. El-Brolosy, M. A. and Stainier, D. Y. R. (2017). Genetic compensation: A phenomenon in search of mechanisms. PLoS Genet 13(7): e1006780.

14. Feig, S. and Lipton, P. (1990). $\mathrm{N}$-methyl-D-aspartate receptor activation and $\mathrm{Ca}^{2+}$ account for poor pyramidal cell structure in hippocampal slices. $J$ Neurochem 55(2): 473-483.

15. Frey, U. and Morris, R. G. (1997). Synaptic tagging and long-term potentiation. Nature 385(6616): 533-536.

16. Garcia-Osta, A., Tsokas, P., Pollonini, G., Landau, E. M., Blitzer, R. and Alberini, C. M. (2006). MuSK expressed in the brain mediates cholinergic responses, synaptic plasticity, and memory formation. J Neurosci 26(30): 7919-7932.

17. Gruart, A., Benito, E., Delgado-García, J. M. and Barco, A. (2012). Enhanced cAMP response element-binding protein activity increases neuronal excitability, hippocampal long-term potentiation, and classical eyeblink conditioning in alert behaving mice. $J$ Neurosci 32(48): 17431-17441.

18. Guzowski, J. F., Lyford, G. L., Stevenson, G. D., Houston, F. P., McGaugh, J. L., Worley, P. F. and Barnes, C. A. (2000). Inhibition of activity-dependent arc protein expression in the rat hippocampus impairs the maintenance of long-term potentiation and the consolidation of long-term memory. J Neurosci 20(11): 3993-4001.

19. Hájos, N., Ellender, T. J., Zemankovics, R., Mann, E. O., Exley, R., Cragg, S. J., Freund, T. F. and Paulsen, O. (2009). Maintaining network activity in submerged hippocampal slices: importance of oxygen supply. Eur J Neurosci 29(2): 319-327.

20. Hsieh, C., Tsokas, P., Serrano, P., Hernández, A. I., Tian, D., Cottrell, J. E., Shouval, H. Z., Fenton, A. A. and Sacktor, T. C. (2017). Persistent increased PKM spatial memory. Neurobiol Learn Mem 138: 135-144.

21. Kelleher, R. J., 3rd, Govindarajan, A., Jung, H. Y., Kang, H. and Tonegawa, S. (2004). Translational control by MAPK signaling in long-term synaptic plasticity and memory. Cell 116(3): 467-479. 
22. Khurana, S. and Li, W. K. (2013). Baptisms of fire or death knells for acute-slice physiology in the age of 'omics' and light? Rev Neurosci 24(5): 527-536.

23. Li, Q., Navakkode, S., Rothkegel, M., Soong, T. W., Sajikumar, S. and Korte, M. (2017). Metaplasticity mechanisms restore plasticity and associativity in an animal model of Alzheimer's disease. Proc Natl Acad Sci U S A 114(21): 5527-5532.

24. Ling, D. S., Benardo, L. S., Serrano, P. A., Blace, N., Kelly, M. T., Crary, J. F. and Sacktor, T. C. (2002). Protein kinase Mzeta is necessary and sufficient for LTP maintenance. Nat Neurosci 5(4): 295-296.

25. Madroñal, N., Gruart, A., Sacktor, T. C. and Delgado-Garcia, J. M. (2010). PKM inhibition reverses learning-induced increases in hippocampal synaptic strength and memory during trace eyeblink conditioning. PLoS One 5(4): e10400.

26. Matthies, H., Schröder, H., Wagner, M., Höllt, V. and Krug, M. (1995). NMDA/R1-antisense oligonucleotide influences the early stage of long-term potentiation in the CA1-region of rat hippocampus. Neurosci Lett 202(1-2): 113-116.

27. Nguyen, P. V., Abel, T., Kandel, E. R. and Bourtchouladze, R. (2000). Strain-dependent differences in LTP and hippocampus-dependent memory in inbred mice. Learn Mem 7(3): 170-179.

28. Opazo, P., Watabe, A. M., Grant, S. G. and O'Dell, T. J. (2003). Phosphatidylinositol 3-kinase regulates the induction of long-term potentiation through extracellular signal-related kinase-independent mechanisms. J Neurosci 23(9): 3679-3688.

29. Operating Manual for Micropump mp6/mp6-pp and Controller. (2014). Bartels Mikrotechnik. www.bartels-mikrotechnik.de.

30. Osten, P., Valsamis, L., Harris, A. and Sacktor, T. C. (1996). Protein synthesis-dependent formation of protein kinase Mzeta in long-term potentiation. J Neurosci 16(8): 2444-2451.

31. Pastalkova, E., Serrano, P., Pinkhasova, D., Wallace, E., Fenton, A. A. and Sacktor, T. C. (2006). Storage of spatial information by the maintenance mechanism of LTP. Science 313(5790): 1141-1144.

32. Pavlowsky, A. and Alarcon, J. M. (2012). Interaction between long-term potentiation and depression in CA1 synapses: temporal constrains, functional compartmentalization and protein synthesis. PLoS One 7(1): e29865.

33. Puzzo, D., Piacentini, R., Fá, M., Gulisano, W., Li Puma, D. D., Staniszewski, A., Zhang, H., Tropea, M. R., Cocco, S., Palmeri, A., Fraser, P., D'Adamio, L., Grassi, C. and Arancio, O. (2017). LTP and memory impairment caused by extracellular $A \beta$ and Tau oligomers is APP-dependent. Elife 6. pii: e26991.

34. Radtke D. B., White A. F., Davis J. V. and Wilde F. D. (1998). Dissolved oxygen. In: National Field Manual for the Collection of Water-Quality Data. US Geological Survey TWRI Book 9. Reston, VA: USGS. 
Please cite this article as: Tsokas et. al., (2019). Antisense Oligodeoxynucleotide Perfusion Blocks Gene Expression of Synaptic Plasticity-related

35. Sacktor, T. C., Osten, P., Valsamis, H., Jiang, X., Naik, M. U. and Sublette, E. (1993). Persistent activation of the zeta isoform of protein kinase $C$ in the maintenance of long-term potentiation. Proc Natl Acad Sci U S A 90(18): 8342-8346.

36. Sajikumar, S., Navakkode, S., Sacktor, T. C. and Frey, J. U. (2005). Synaptic tagging and cross-tagging: the role of protein kinase $M \zeta$ in maintaining long-term potentiation but not long-term depression. J Neurosci 25(24): 5750-5756.

37. Selcher, J. C., Weeber, E. J., Christian, J., Nekrasova, T., Landreth, G. E. and Sweatt, J. D. (2003). A role for ERK MAP kinase in physiologic temporal integration in hippocampal area CA1. Learn Mem 10(1): 26-39.

38. Sharma, M. and Sajikumar, S. (2018). G9a/GLP complex acts as a bidirectional switch to regulate metabotropic glutamate receptor-dependent plasticity in hippocampal CA1 pyramidal neurons. Cereb Cortex 29(7): 2932-2946.

39. Shetty, M. S., Sharma, M., Hui, N. S., Dasgupta, A., Gopinadhan, S.and Sajikumar S. (2015). Investigation of Synaptic Tagging/Capture and Cross-capture using Acute Hippocampal Slices from Rodents. J Vis Exp. (103): 53008.

40. Tian, D., Dmitrieva, R. I., Doris, P. A., Crary, J. F., Sondhi, R., Sacktor, T. C. and Bergold, P. J. (2008). Protein kinase $\mathrm{M}$ zeta regulation of $\mathrm{Na} / \mathrm{K}$ ATPase: a persistent neuroprotective mechanism of ischemic preconditioning in hippocampal slice cultures. Brain Res 1213: 127-139.

41. Ting, J. T., Lee, B. R., Chong, P., Soler-Llavina, G., Cobbs, C., Koch, C., Zeng, H. and Lein, E. (2018). Preparation of acute brain slices using an optimized N-Methyl-D-glucamine protective recovery method. J Vis $\operatorname{Exp}(132)$. doi: 10.3791/53825.

42. Tsokas, P., Grace, E. A., Chan, P., Ma, T., Sealfon, S. C., Iyengar, R., Landau, E. M. and Blitzer, R. D. (2005). Local protein synthesis mediates a rapid increase in dendritic elongation factor $1 \mathrm{~A}$ after induction of late long-term potentiation. J Neurosci 25(24): 5833-5843.

43. Tsokas, P., Hsieh, C., Yao, Y., Lesburguères, E., Wallace, E. J. C., Tcherepanov, A., Jothianandan, D., Hartley, B. R., Pan, L., Rivard, B., Farese, R. V., Sajan, M. P., Bergold, P. J., Hernández, A. I., Cottrell, J. E., Shouval, H. Z., Fenton, A. A. and Sacktor, T. C. (2016). Compensation for $\mathrm{PKM} \zeta$ in long-term potentiation and spatial long-term memory in mutant mice. Elife 5. pii: e14846.

44. Villers A and Ris L. (2013). Improved preparation and preservation of hippocampal mouse slices for a very stable and reproducible recording of long-term potentiation. J Vis Exp. (76): 50483.

45. Volk, L. J., Bachman, J. L., Johnson, R., Yu, Y. and Huganir, R. L. (2013). PKM- $\underline{\text { is not }}$ required for hippocampal synaptic plasticity, learning and memory. Nature 493(7432): 420-423.

46. Wang, T. and Kass, I. S. (1997). Preparation of brain slices. Methods Mol Biol 72: 1-14.

47. Weng, W., Li, D., Peng, C. and Behnisch, T. (2018). Recording synaptic plasticity in acute hippocampal slices maintained in a small-volume recycling-, perfusion-, and submersion-type chamber system. $J$ Vis Exp (131). 